\title{
The structure of strongly tilted current sheets in the Earth magnetotail
}

\author{
I. Y. Vasko ${ }^{1}$, A. V. Artemyev ${ }^{1}$, A. A. Petrukovich ${ }^{1}$, R. Nakamura ${ }^{2}$, and L. M. Zelenyi ${ }^{1}$ \\ ${ }^{1}$ Space Research Institute of Russian Academy of Sciences, Moscow, Russia \\ ${ }^{2}$ Institute of Space Research of Austrian Academy of Sciences, Graz, Austria \\ Correspondence to: I. Y. Vasko (vaskoiy@yandex.ru)
}

Received: 7 September 2013 - Revised: 12 December 2013 - Accepted: 17 January 2014 - Published: 20 February 2014

\begin{abstract}
We investigate strongly tilted (in the $y-z$ GSM plane) current sheets (CSs) in the Earth magnetotail using data from the Cluster mission. We analyze 29 CS crossings observed in 2001-2004. The characteristic current density, magnetic field at the CS boundary and the CS thickness of strongly tilted CSs are similar to those reported previously for horizontal (not tilted) CSs. We confirm that strongly tilted CSs are generally characterized by a rather large northward component of the magnetic field. The field-aligned current in strongly tilted CSs is on average two times larger than the transverse current. The proton adiabaticity parameter, $\kappa_{\mathrm{p}}$, is larger than 0.5 in $85 \%$ of strongly tilted CSs due to the large northward magnetic field. Thus, the proton dynamics is stochastic for 18 current sheets with $0.5<\kappa_{\mathrm{p}}<3$ and protons are magnetized for 6 sheets with $\kappa_{\mathrm{p}}>3$, whereas electrons are magnetized for all observed current sheets. Strongly tilted CSs provide a unique opportunity to measure the electric field component perpendicular to the CS plane. We find that most of the electric field perpendicular to the CS plane is due to the decoupling of electron and ion motions (plasma polarization). For $27 \mathrm{CSs}$ we determine profiles of the electrostatic potential, which is due to the plasma polarization. Drops in the potential between the neutral plane and the CS boundary are within the range of $200 \mathrm{~V}$ to $12 \mathrm{kV}$, while maximal values of the electric field are within the range of $0.2 \mathrm{mV} \mathrm{m}^{-1}$ to $8 \mathrm{mV} \mathrm{m}^{-1}$. For $16 \mathrm{CSs}$ the observed potentials are in accordance with Ohm's law, if the electron current density is assumed to be comparable to the total current density. In 15 of these CSs the profile of the polarization potential is approximately symmetric with respect to the neutral plane and has minimum therein.
\end{abstract}

Keywords. Magnetospheric physics (magnetotail; magnetotail boundary layers)

\section{Introduction}

The current sheet (CS) is a fundamental element of the Earth magnetotail (Ness, 1965). The local structure of the CS magnetic field is roughly described by the modified Harris model (Harris, 1962): $\boldsymbol{B}=B_{0} \tanh \left(z / L_{z}\right) \boldsymbol{e}_{x}+B_{y} \boldsymbol{e}_{y}+B_{z} \boldsymbol{e}_{z}$, where $L_{z}$ is the CS thickness, and $B_{0}, B_{y}$ and $B_{z}$ are constants $(x, y$, and $z$ define the GSM system). In this model the current density is in the dawn-dusk direction and the CS normal vector (direction of inhomogeneity) is along the $z$ axis.

Cluster measurements allow for the determination of local CS characteristics: the CS orientation (i.e., the normal vector), the flapping velocity, etc. (Zhang et al., 2002; Petrukovich et al., 2003; Shen et al., 2003; Sergeev et al., 2004; Runov et al., 2005). Zhang et al. (2002) have shown that, in particular CS crossings, the CS normal vector is significantly inclined toward the $y$ axis. Sergeev et al. (2004) have shown that such tilted CSs are frequently observed at the magnetotail flanks. The specific property of tilted CSs is the dominance of the northward (or southward) component of the current density (i.e., $j_{z}$ ) (Sergeev et al., 2004). In a sequence of CS crossings, $j_{z}$ has different signs for neighboring tilted CSs (Sergeev et al., 2004). Zhang et al. (2005) have presented simultaneous observations of the tilted CS by the Cluster mission at $X \sim-17 R_{\mathrm{E}}$ and by the Double Star mission at $X \sim-11 R_{\mathrm{E}}$. These observations showed that the CS deformation is large-scale in the Earth-Sun direction. Petrukovich et al. (2008) have suggested and Rong et al. (2010) have investigated the model of the wavy CS deformation explaining the appearance of tilted CSs:

$$
\boldsymbol{B}=B_{0} \tanh \left(\frac{z-z_{0}\left(\left(y-v_{0} t\right) / \lambda\right)}{L_{z}}\right) \boldsymbol{e}_{x}+B_{y} \boldsymbol{e}_{y}+B_{z} \boldsymbol{e}_{z},
$$


where $z_{0}\left(\left(y-v_{0} t\right) / \lambda\right)$ determines the deformation of the CS neutral plane, $\lambda$ is the characteristic wavelength, $v_{0}$ is the phase velocity and $B_{y} \ll B_{z}$ (Petrukovich et al., 2006), so that magnetic field lines lie almost in the $X Z$ planes. Figure 1 presents a schematic view of the CS geometry according to model 1. Tilted CSs are observed as Cluster crosses leading or trailing fronts of the wavy neutral plane. One of the tilted CSs is marked by blue dashed lines in Fig. 1 .

The CS structure determines the magnetotail dynamics (Baumjohann et al., 2007) and the rate of charged particle acceleration (Birn et al., 2012). In particular, the CS tearing instability can be responsible for the substorm onset (see Schindler, 2006, and references therein). Thus, detailed information about the CS structure is required to investigate various transient processes in the magnetotail. Cluster data have substantially advanced our understanding of the equilibrium structure of horizontal CSs (with the normal vector along the $z$ axis) (see e.g., Artemyev and Zelenyi, 2012, and references therein). On the other hand, there is still no detailed study of the equilibrium structure of tilted CSs.

In the present paper we study the structure of tilted CSs with the normal vector $\boldsymbol{n}$ directed almost along the $y$ axis, i.e., the angle $\gamma$ of the CS inclination is smaller than $30^{\circ}$ (see Fig. 1). In these strongly tilted CSs, the current flows almost along the $z$ axis. Since, in tilted CSs, $B_{y} \ll B_{z}$ (Petrukovich et al., 2006), there is significant field-aligned current near the neutral plane (Shen et al., 2008). In this respect strongly titled CSs are similar to horizontal CSs with substantial $B_{y}$ component (Rong et al., 2012). In this paper we compare properties of strongly tilted and horizontal CSs and discuss the nature of the current in strongly tilted CSs.

In horizontal CSs the electric field due to the decoupling of electron and ion motions (plasma polarization) is along the $z$ axis (Zelenyi et al., 2004; Schindler et al., 2012). This field has not been observed, since Cluster measures electric field components in the spin plane (approximately $X Y$ GSE). In strongly tilted CSs the polarization electric field is almost along the $y$ axis and can be reliably measured by Cluster. Thus, strongly tilted CSs allow one to address the important problem of the distribution of the polarization electric field.

In Sect. 2 we describe our data set, approach and selection criteria. In Sect. 3 we compare properties of strongly tilted and horizontal CSs. In Sect. 4 we suggest a technique that allows one to extract the polarization electric field from the electric field measured by Cluster. We discuss also the theoretical profiles of the polarization potential based on the Ohm's law. In Sect. 5 we obtain the profiles of the polarization electric field, determine the profiles of the corresponding electrostatic potential, and compare them with the theoretical profiles.

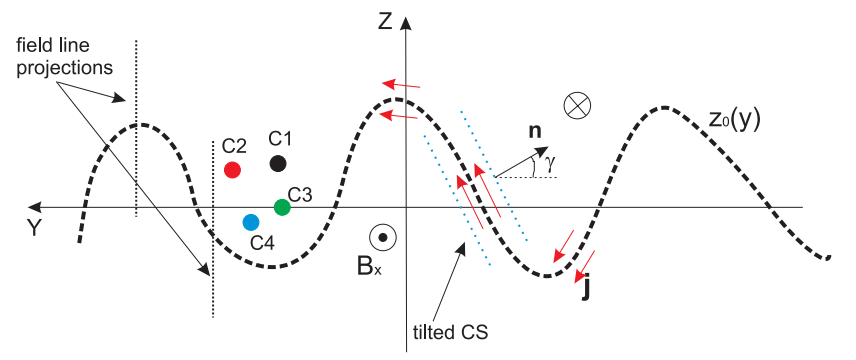

Fig. 1. The model of the wavy CS: thick dashed curve $z=z_{0}(y)$ is the bent neutral plane; black dashed vertical lines show projections of the magnetic field lines onto the $Y Z$ plane; circles show the direction of $B_{x}$; red arrows show the current density $\boldsymbol{j}$; colored points $\mathrm{C} 1-\mathrm{C} 4$ present Cluster; blue dashed lines show a tilted CS; $\boldsymbol{n}$ is the CS normal vector; the angle $\gamma$ determines the CS inclination.

\section{The Data and approach}

We investigate 29 crossings of the magnetotail CS by Cluster observed in 2001-2004 (Table 1). The events for 2001 and 2004 can be found in the large database http://geo.phys. spbu.ru/ runov/, and we have included eight events for 2002 and 2003. We use the following data from the Cluster Active Archive (http://caa.estec.esa.int/caa/): FGM magnetic field with a $4 \mathrm{~s}$ time resolution (Balogh et al., 2001), CIS/CODIF proton moments (Rème et al., 2001), PEACE electron moments (Owen et al., 2001), EFW electric field with a $4 \mathrm{~s}$ time resolution (Gustafsson et al., 2001).

We use CS 29, presented in Fig. 2, to describe methods applied in our analysis. Panels $\mathrm{a}_{\mathrm{L}}-\mathrm{c}_{\mathrm{L}}$ show the $x, y$, and $z$ components of the magnetic field $\boldsymbol{B}^{(\alpha)}$ measured at the spacecraft $C \alpha(\alpha=1,2,3,4)$ and the same components of the magnetic field $\boldsymbol{B}_{\mathrm{c}}$ in the barycenter, $\boldsymbol{B}_{\mathrm{c}}=0.25 \sum_{\alpha=1}^{\alpha=4} \boldsymbol{B}^{(\alpha)}$. Panel $\mathrm{d}_{\mathrm{L}}$ presents the $y$ component of the electric $\boldsymbol{E}^{(\alpha)}$ measured at spacecraft $C \alpha(\alpha=1,2,3,4)$. Panels $\mathrm{e}_{\mathrm{L}}-\mathrm{h}_{\mathrm{L}}$ show proton and electron bulk velocities $\boldsymbol{v}_{\mathrm{p}, \mathrm{e}}$, densities $n_{\mathrm{p}, \mathrm{e}}$ and temperatures $T_{\mathrm{p}, \mathrm{e}}$. The proton moments are provided by $\mathrm{C} 1$, while the electron moments are provided by $\mathrm{C} 2$.

Cluster four-point measurements allow for the determination of the current density by the curlometer technique $\boldsymbol{j}_{\mathrm{c}}=\mu_{0}^{-1}$ curl $\boldsymbol{B}$ (Chanteur, 2000) ( $\mu_{0}$ is the permeability of vacuum). The accuracy of the curlometer technique depends on the tetrahedron shape and size (see, e.g., Robert, 2000; Vallat et al., 2005). In all CS crossings selected for the present study both elongation and planarity of the Cluster tetrahedron are smaller than 0.35 , i.e., the tetrahedron shape is close to perfect. Thus, the curlometer technique can underestimate the current density only due to finite separation between spacecraft.

We study each CS crossing in the local coordinate system $(\boldsymbol{l}, \boldsymbol{m}, \boldsymbol{n})$ (Runov et al., 2005). The maximum variance direction $\boldsymbol{l}$ is determined via minimum variance analysis (MVA) (see, e.g., Sonnerup and Sheible, 2000) using the magnetic 
Table 1. List of events. In the rows presenting $\left\langle V_{n}\right\rangle$ and $\left\langle j_{\text {tim }}\right\rangle$, the numbers in parentheses are root mean square deviations $\delta V_{n} /\left\langle V_{n}\right\rangle$ and $\delta j_{\text {tim }} /\left\langle j_{\text {tim }}\right\rangle$. The CS thickness $L$ is given in megameters, $\mathrm{Mm}=10^{3} \mathrm{~km}$.

\begin{tabular}{|c|c|c|c|c|c|c|c|c|c|c|}
\hline Date (UT) & $\begin{array}{r}\left\langle B_{m}\right\rangle \\
\left(\left\langle B_{n}\right\rangle\right) \\
\mathrm{nT}\end{array}$ & $\begin{array}{r}B_{l}^{\min } \\
\left(B_{l}^{\max }\right) \\
\quad \mathrm{nT}\end{array}$ & $B_{\text {ext }}$ & $\mathrm{km} \mathrm{s}^{-1}$ & $\Delta t$ & $\mathrm{Mm}$ & $\left\langle j_{\mathrm{cm}}\right\rangle$ & $\begin{array}{r}\left\langle j_{\text {tim }}\right\rangle \\
\mathrm{nA} \mathrm{m}^{-2}\end{array}$ & $\left\langle j_{p m}\right\rangle$ & $\left\langle j_{e m}\right\rangle$ \\
\hline 1. 24 Jul 2001: 18:05-18:09 & $5.9(1.6)$ & $-15(29)$ & 38 & $49(0.15)$ & 90 & 2.2 & 10.8 & $17.6(0.25)$ & -15.4 & 22.6 \\
\hline 2. 27 Jul 2001: 10:40-10:45 & $1(1.1)$ & $-9.3(6.5)$ & 29 & $31(0.03)$ & 210 & 3.3 & 2.5 & $2.6(0.09)$ & 2.2 & -1 \\
\hline 3. 5 Aug 2001: 14:46-14:49 & $15.4(2.1)$ & $-12.3(5.6)$ & 39 & $34(0.09)$ & 90 & 1.5 & 6.1 & $7.4(0.23)$ & -0.6 & 7.6 \\
\hline 4. 12 Aug 2001: 15:26-15:29 & $9.8(3)$ & $-6.4(17.3)$ & 40 & $24(0.09)$ & 100 & 1.2 & 6.7 & $11.6(0.32)$ & -1.6 & 17.2 \\
\hline 5. 12 Aug 2001: 15:29-15:32 & $-6.5(1.7)$ & $-7.6(12.1)$ & 40 & $29(0.03)$ & 80 & 1.2 & 7.5 & $12.4(0.1)$ & 7.2 & 12 \\
\hline 6. 14 Sep 2001: 22:53-22:57 & $7.2(0.2)$ & $-20.7(12.2)$ & 32 & $22(0.07)$ & 125 & 1.4 & 9.9 & $13.5(0.09)$ & -6.1 & 42.9 \\
\hline 7. 14 Sep 2001: 23:08-23:12 & $7.1(1.5)$ & $-6.9(10.3)$ & 32 & $23(0.08)$ & 60 & 0.7 & 6.2 & $12.3(0.3)$ & -9.2 & -12.5 \\
\hline 8. 24 Sep 2001: 08:01-08:06 & $-0.9(1.6)$ & $-9.1(28.8)$ & 27 & $24(0.1)$ & 125 & 1.5 & 9.7 & $9.2(0.18)$ & -4 & 13.4 \\
\hline 9. 20 Oct 2001: 09:36-09:41 & $3.4(1.1)$ & $-20.5(27.3)$ & 28 & $32(0.08)$ & 150 & 2.4 & 6.6 & $6.4(0.08)$ & -4.8 & 7.7 \\
\hline 10. 20 Oct 2001: 09:41-09:45 & $-2.4(1.2)$ & $-16.3(27)$ & 26 & $57(0.05)$ & 140 & 4.0 & 6.6 & $7.1(0.1)$ & -2.8 & 17.2 \\
\hline 11. 20 Oct 2001: 09:58-10:01 & $-1.6(1.1)$ & $-8(11.3)$ & 26 & $63(0.04)$ & 35 & 1.1 & 5.1 & $8.3(0.23)$ & 0.3 & 11 \\
\hline 12. 20 Oct 2001: 10:07-10:09 & $-1.1(0.6)$ & $-21.7(3.5)$ & 26 & $65(0.13)$ & 70 & 2.3 & 4.4 & $5.4(0.11)$ & 1 & 5.1 \\
\hline 13. 30 Jul 2002: 13:45-14:07 & $8.1(4.4)$ & $-1.5(22)$ & 33 & $14(0.25)$ & 1000 & 7.0 & 1.4 & $1.5(0.12)$ & 3 & 2.6 \\
\hline 14. 4 Aug 2002: 15:20-15:35 & $4.8(2.3)$ & $-15(17.5)$ & 28 & $16(0.34)$ & 800 & 6.6 & 2.4 & $3.5(0.12)$ & -3.4 & 7.1 \\
\hline 15. 9 Aug 2002: 06:03-06:12 & $7.8(0.4)$ & $-1.2(29.7)$ & 34 & $15(0.11)$ & 400 & 3.0 & 6.4 & $7.8(0.18)$ & -3.6 & 10 \\
\hline 16. 9 Sep 2002: 04:10-04:40 & $6.5(1.4)$ & $-10.3(24.6)$ & 30 & $9(0.12)$ & 800 & 3.5 & 3.9 & $4.5(0.19)$ & 6.4 & 6.1 \\
\hline 17. 27 Jul 2003: 05:53-05:55 & $-19.3(1.9)$ & $-15(7.6)$ & 42 & $80(0.09)$ & 30 & 1.2 & 11.1 & $12.4(0.08)$ & 10.4 & -14.9 \\
\hline 18. 5 Aug 2003: 19:36-19:38 & $-3.1(0.5)$ & $-1.6(15.2)$ & 35 & $42(0.07)$ & 45 & 1.0 & 7.1 & $7.2(0.15)$ & -30.5 & 21.5 \\
\hline 19. 15 Aug 2003: 12:19-12:23 & $1.5(0.9)$ & $-20.8(7.1)$ & 33 & $36(0.1)$ & 340 & 6.2 & 4 & $4.2(0)$ & 0.9 & 5.1 \\
\hline 20. 22 Sep 2003: 06:45-06:52 & $9.9(3.2)$ & $-5.7(11.7)$ & 29 & $17(0.35)$ & 350 & 2.9 & 3.5 & $3(0.16)$ & 1.1 & 1.5 \\
\hline 21. 12 Jul 2004: 20:17-20:19 & $7.6(0.6)$ & $-7.6(5.5)$ & 26 & $120(0.09)$ & 40 & 2.4 & 2.8 & $2.5(0.15)$ & 0.4 & -3.5 \\
\hline 22. 13 Jul 2004: 00:53-00:55 & $9.6(2.8)$ & $-11.5(15)$ & 33 & $24(0.1)$ & 30 & 0.4 & 27.3 & $52.1(0.16)$ & -8.4 & 121 \\
\hline 23. 13 Jul 2004: 00:55-00:57 & $7.7(-1.7)$ & $-13.6(21)$ & 31 & $30(0.04)$ & 25 & 0.4 & 29.8 & $50(0.31)$ & 21.7 & 30 \\
\hline 24. 22 Jul 2004: 12:08-12:13 & $7.9(-0.04)$ & $-10.4(9.6)$ & 38 & $46(0.16)$ & 120 & 2.8 & 3.6 & $4.6(0.05)$ & 0.6 & 4.9 \\
\hline 25. 22 Jul 2004: $14: 32-14: 36$ & $6.7(2.2)$ & $-10.7(13.5)$ & 42 & $24(0.33)$ & 150 & 1.8 & 4.7 & $6(0.3)$ & 9.2 & 4 \\
\hline 26. 22 Jul 2004: 15:05-15:07 & $3.9(1)$ & $-10.5(14.3)$ & 37 & $84(0.16)$ & 55 & 2.3 & 5.2 & $5.5(0.03)$ & -15.6 & 22 \\
\hline 27. 3 Aug 2004: 09:07-09:17 & $6.1(0.8)$ & $-11.7(9.5)$ & 29 & $11(0.24)$ & 430 & 2.3 & 4.5 & $3.8(0.13)$ & 0.4 & 2.1 \\
\hline 28. 3 Aug 2004: 09:17-09:20 & $-5.8(1.2)$ & $-12.8(13)$ & 29 & $24(0.09)$ & 220 & 2.6 & 6.5 & $6.8(0.07)$ & 1.9 & 5.2 \\
\hline 29. 7 Sep 2004: 14:18-14:26 & $-10.9(4.8)$ & $-4.4(15.1)$ & 34 & $29(0.1)$ & 80 & 1.2 & 7.6 & $11(0.18)$ & 1.5 & 6.3 \\
\hline
\end{tabular}

field $\boldsymbol{B}_{\mathrm{c}}$ in the barycenter. The vector $\boldsymbol{m}$ is directed along the component of the curlometer current density perpendicular to $\boldsymbol{l}$. The CS normal vector is $\boldsymbol{n}=[\boldsymbol{l}, \boldsymbol{m}]$.

In strongly tilted CSs $\boldsymbol{n}$ is directed almost along the $y$ axis (see criteria below). Therefore we calculate the perpendicular electric field $E_{n}^{(\alpha)}=\boldsymbol{n} \boldsymbol{E}^{(\alpha)}$ by neglecting $x$ and $z$ components of $\boldsymbol{E}^{(\alpha)}$, i.e., $E_{n}^{(\alpha)}=n_{y} E_{y}^{(\alpha)}$. Figure 2 presents the $\boldsymbol{l}, \boldsymbol{m}, \boldsymbol{n}$ components of magnetic fields $\boldsymbol{B}^{(\alpha)}, \boldsymbol{B}_{\mathrm{c}}$ (panels a ${ }^{-}$ $\mathrm{c}_{\mathrm{R}}$ ) and the electric field $E_{n}^{(\alpha)}$ (panel $\mathrm{d}_{\mathrm{R}}$ ) for CS 29. Panels $e_{\mathrm{R}}, \mathrm{f}_{\mathrm{R}}$ show $\boldsymbol{l}, \boldsymbol{m}, \boldsymbol{n}$ components of the curlometer current $\boldsymbol{j}_{\mathrm{c}}$ as well as its field-aligned $j_{\|}=\left(\boldsymbol{j}_{\mathrm{c}} \boldsymbol{B}_{\mathrm{c}}\right) /\left|\boldsymbol{B}_{\mathrm{c}}\right|$ and transverse $j_{\perp}=\left|\boldsymbol{j}_{\mathrm{c}}-j_{\|} \boldsymbol{B}_{\mathrm{c}} /\right| \boldsymbol{B}_{\mathrm{c}}||$ components. One can see that the field-aligned current substantially exceeds the transverse one. We determine minimum $B_{l}^{\min }$ and maximum $B_{l}^{\max }$ values of $B_{l}$ (panel $\mathrm{a}_{\mathrm{R}}$ ), the magnetic field at the CS boundary $B_{0}=\max \left(\left|B_{l}^{\min }\right|,\left|B_{l}^{\max }\right|\right)$ and averaged values of $B_{n}$ and $B_{m}$ across the CS central region, $\left|B_{l}\right|<5 \mathrm{nT}$. Furthermore, all averaged values are denoted by angle brackets. Table 1 presents $\left\langle B_{n}\right\rangle,\left\langle B_{m}\right\rangle$ and $B_{l}^{\min }, B_{l}^{\max }$ for all CSs from our data set.
The timing method can be used to determine the CS normal vector, $\boldsymbol{n}_{\text {tim }}$, and the velocity, $V_{n}$, of the CS motion along $\boldsymbol{n}_{\text {tim }}$ (Dunlop and Woodward, 2000; Schwartz, 2000). The timing technique is illustrated for CS 29 in Fig. 2a $a_{R}$. The time delays, $t_{i}-t_{k}$, between different spacecraft are used to determine $\boldsymbol{n}_{\text {tim }}$ and $V_{n}$ at fixed $B_{l}$ (shown in Fig. $2 \mathrm{a}_{\mathrm{R}}$ for $\left.B_{l}=0\right)$. We determine $V_{n}$ and $\boldsymbol{n}_{\text {tim }}$ with $1 \mathrm{nT} B_{l}$-step across the CS and calculate the averaged value $\left\langle V_{n}\right\rangle$ across the CS and the corresponding root mean square deviation $\delta V_{n}$. In our $29 \mathrm{CSs}$ the timing velocity is rather stable: $\delta V_{n} /\left\langle V_{n}\right\rangle<0.35$, while $\delta V_{n} /\left\langle V_{n}\right\rangle>0.15$ only in seven CSs. We estimate the CS thickness as $L=\left\langle V_{n}\right\rangle \Delta t / 2$, where $\Delta t$ is the duration of the CS crossing (see panel $\mathrm{a}_{\mathrm{R}}$ ). Table 1 presents $\left\langle V_{n}\right\rangle$, $\delta V_{n} /\left\langle V_{n}\right\rangle, \Delta t$ and $L$.

The current density can be estimated by the timing technique as $j_{\text {tim }}^{(\alpha)}=c\left(B_{l}^{(\alpha)}(t+\delta t)-B_{l}^{(\alpha)}(t)\right) / 4 \pi\left\langle V_{n}\right\rangle \delta t$, where $\delta t$ is the time resolution of magnetic field measurements. In contrast to the curlometer technique, the accuracy of the timing technique is not affected by the finite separation between the spacecraft. Figure $2 g_{R}$ presents $j_{\text {tim }}^{(\alpha)}$ for CS 29. Petrukovich et al. (2008) have pointed out that for strongly 

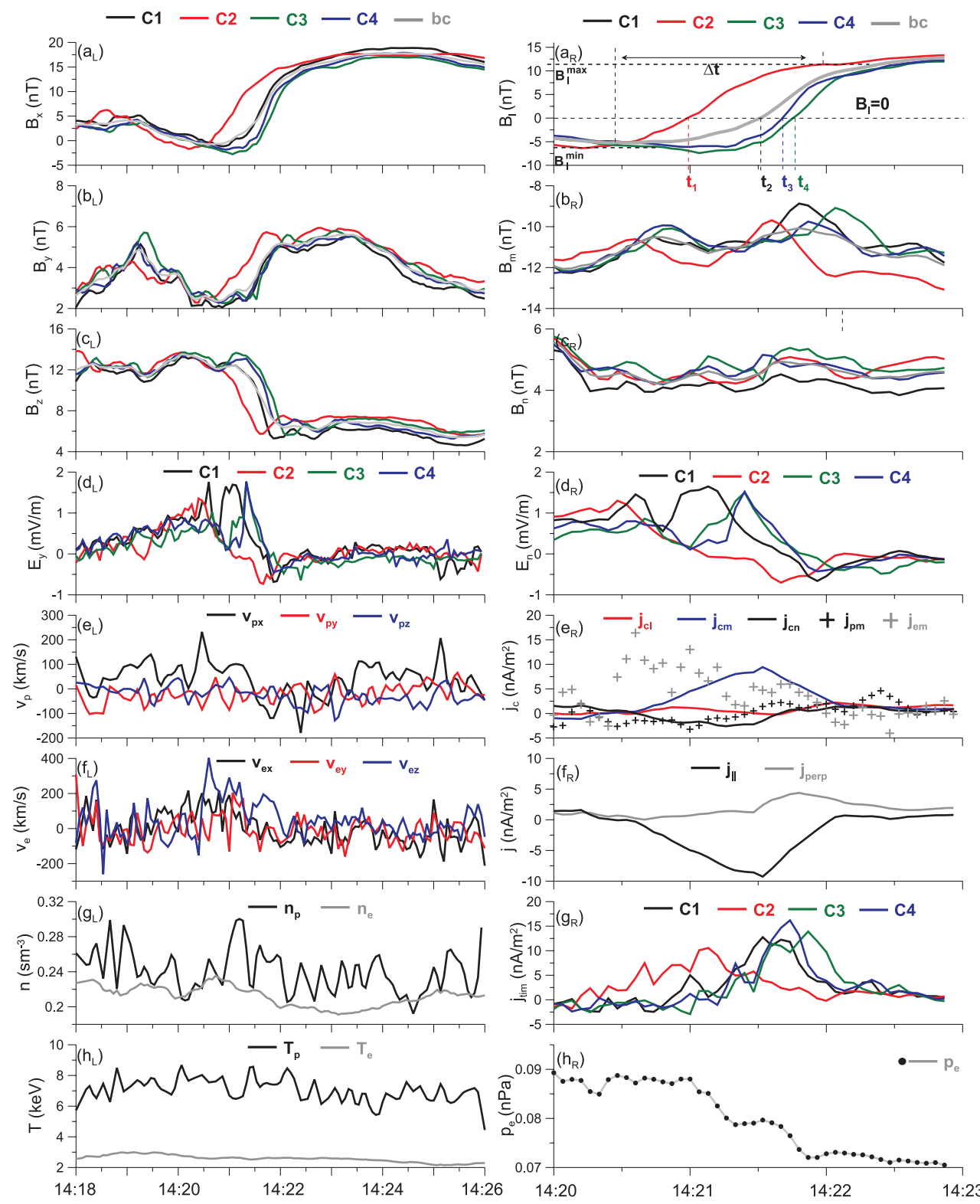

Fig. 2. Right and left panels present parameters of CS 29 in GSM and local coordinate systems, respectively. $\left(\mathbf{a}_{\mathrm{L}, \mathrm{R}}-\mathbf{c}_{\mathrm{L}, \mathrm{R}}\right) X, Y, Z$ and $\boldsymbol{l}, \boldsymbol{m}, \boldsymbol{n}$ components of the magnetic field $\boldsymbol{B}^{(\alpha)}$ measured at spacecraft $C \alpha(\alpha=1-4)$ and the same components of the magnetic field $\boldsymbol{B}_{\mathrm{c}}$ in the barycenter $(\mathrm{bc}) ;\left(\mathbf{d}_{\mathrm{L}, \mathrm{R}}\right) y$ and $\boldsymbol{n}$ components of electric fields $\boldsymbol{E}^{(\alpha)}$ (measured at $\left.C \alpha\right) ;\left(\mathbf{e}_{\mathrm{L}}, \mathbf{f}_{\mathrm{L}}\right)$ components of proton and electron bulk velocities $\boldsymbol{v}_{\mathrm{p}}$ and $\boldsymbol{v}_{\mathrm{e}} ;\left(\mathbf{g}_{\mathrm{L}}, \mathbf{h}_{\mathrm{L}}\right)$ proton and electron densities $\left(n_{\mathrm{p}, \mathrm{e}}\right)$ and temperatures $\left(T_{\mathrm{p}, \mathrm{e}}\right) ;\left(\mathbf{e}_{\mathrm{R}}\right) \boldsymbol{l}, \boldsymbol{m}, \boldsymbol{n}$ components of the curlometer current density $\boldsymbol{j}_{\mathrm{c}}$; proton $j_{\mathrm{pm}}$ and electron $j_{\mathrm{em}}$ current densities along vector $\boldsymbol{m} ;\left(\mathbf{f}_{\mathrm{R}}\right)$ field-aligned $j_{\|}$and perpendicular $j_{\perp}$ components of the curlometer current $\boldsymbol{j}_{\mathrm{c}} ;\left(\mathbf{g}_{\mathrm{R}}\right)$ current densities $j_{\text {tim }}^{(\alpha)}$ determined by the timing method; $\left(\mathbf{h}_{\mathrm{R}}\right)$ electron pressure $p_{\mathrm{e}}=n_{\mathrm{e}} T_{\mathrm{e}}$. We use the proton moments provided by $\mathrm{C} 1$ and electron moments provided by $\mathrm{C} 2$.

tilted CSs, the maximum of the current density can be located out of the the neutral plane. For example, Fig. 3 shows profiles of curlometer and timing current densities for CS 29. The curlometer current $j_{\mathrm{cm}}$ has maximum at $B_{l}=0$, while maxima of timing currents $j_{\text {tim }}^{(\alpha)}$ are indeed displaced from $B_{l}^{(\alpha)}=0$. We calculate averaged values of $j_{\mathrm{cm}}, j_{\|}, j_{\perp}$ and $j_{\text {tim }}^{(\alpha)}$ over $5 \mathrm{nT}$ vicinities of $B_{l}$ values, where respectively $j_{\mathrm{cm}}$ and $j_{\text {tim }}^{(\alpha)}$ reach maxima. Table 1 presents $\left\langle j_{\mathrm{cm}}\right\rangle,\left\langle j_{\text {tim }}\right\rangle$ and $\delta j_{\text {tim }} /\left\langle j_{\text {tim }}\right\rangle$, where $\left\langle j_{\text {tim }}\right\rangle=0.25 \sum_{\alpha}\left\langle j_{\text {tim }}^{(\alpha)}\right\rangle$ and $\delta j_{\text {tim }}$ is the root mean square deviation of $\left\langle j_{\text {tim }}^{(\alpha)}\right\rangle$ from $\left\langle j_{\text {tim }}\right\rangle$.

In the CSs of our data set, proton and electron densities can differ up to $40 \%$ as for CS 29 (see Fig. $2 \mathrm{~g}_{\mathrm{L}}$ ). In the present paper we use the electron density as the estimate of the actual plasma density (see discussion in Sect. 5). The 

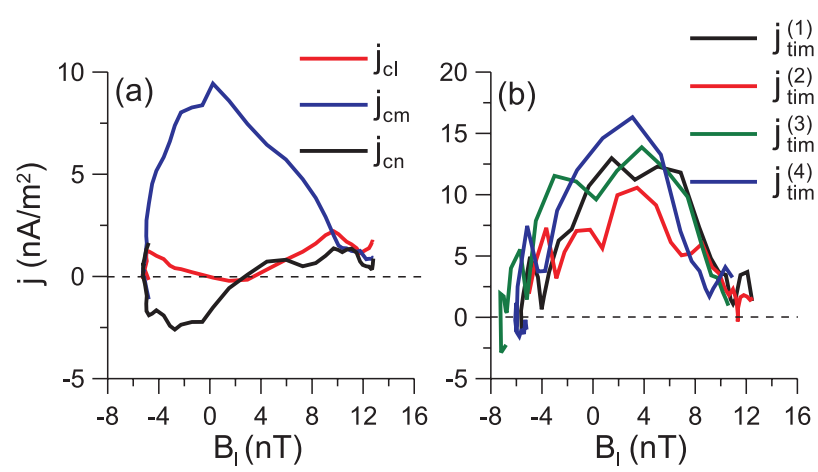

Fig. 3. CS 29: (a) components $j_{\mathrm{cl}}, j_{\mathrm{cm}}, j_{\mathrm{cn}}$ of the curlometer current $\boldsymbol{j}_{\mathrm{c}}$ and particle currents $j_{\mathrm{pm}}$ and $j_{\mathrm{em}}$ across the CS; (b) timing currents $j_{\text {tim }}^{(\alpha)}$ across the CS.

proton and electron current densities along vector $\boldsymbol{m}$ are determined as $j_{\mathrm{pm}}=e n_{\mathrm{e}}\left(\boldsymbol{v}_{\mathrm{p}}, \boldsymbol{m}\right)$ and $j_{\mathrm{em}}=-e n_{\mathrm{e}}\left(\boldsymbol{v}_{\mathrm{e}}, \boldsymbol{m}\right)$. Figure $2 \mathrm{e}_{\mathrm{R}}$ shows that the electron current significantly exceeds the proton one for CS 29. In our analysis we use the averaged values $\left\langle j_{\mathrm{pm}}\right\rangle$ and $\left\langle j_{\mathrm{em}}\right\rangle$ of proton and electron current densities, respectively. The proton current is averaged over $5 \mathrm{nT}$ vicinity of the $B_{l}$ value, where the maximum is reached by $j_{\text {tim }}^{(1)}$ (since proton moments are provided by $\mathrm{C} 1$ ). The electron current is averaged over $5 \mathrm{nT}$ vicinity of the $B_{l}$ value, where the maximum is reached by $j_{\text {tim }}^{(2)}$. Figure $2 h_{R}$ presents the profile of the electron pressure $p_{\mathrm{e}}=n_{\mathrm{e}} T_{\mathrm{e}}$. The electron pressure reaches the maximum at $B_{l}^{(2)}=0$, i.e., as $\mathrm{C} 2$ crosses the neutral plane (since electron moments are provided by $\mathrm{C} 2$ ). The magnetic field in the tail lobes is estimated as $B_{\mathrm{ext}}^{2}=\left\langle 8 \pi\left(n_{\mathrm{p}} T_{\mathrm{p}}+n_{\mathrm{p}} T_{\mathrm{e}}\right)+\boldsymbol{B}^{2}\right\rangle$, where angle brackets denote averaging across the CS. Table 1 presents $\left\langle j_{\mathrm{pm}}\right\rangle,\left\langle j_{\mathrm{em}}\right\rangle$ and $B_{\text {ext }}$.

The investigation of the CS equilibrium structure requires the selection of "close to perfect" CS crossings. We have selected CS crossings using the following criteria:

1. The CS has an approximately 1D planar structure.

a. The magnetic field changes similarly at the locations of four spacecraft (Runov et al., 2006). The timing currents $j_{\text {tim }}^{(\alpha)}$ determined at different spacecraft are close to each other, $\delta j_{\text {tim }} /\left\langle j_{\text {tim }}\right\rangle<$ 0.3 .

b. $j_{\mathrm{cm}} \gg j_{\mathrm{cl}}, j_{\mathrm{cn}}$

c. CS normal vectors $\boldsymbol{n}$ and $\boldsymbol{n}_{\text {tim }}$ determined by two different techniques are close to each other (Runov et al., 2006), i.e., $\left(\boldsymbol{n},\left\langle\boldsymbol{n}_{\text {tim }}\right\rangle\right)>0.95$ (angle brackets denote averaging across the $\mathrm{CS}$ ).

2. The CS is strongly tilted, $n_{y}>0.85\left(\gamma<30^{\circ}\right)$.

3. The CS inclination is steady, i.e., normal vectors $\boldsymbol{n}_{\text {tim }}$ determined with $1 \mathrm{nT} B_{l}$-step are close to the $y$ axis, $\left(\boldsymbol{n}_{\mathrm{tim}}, \boldsymbol{e}_{y}\right)>0.8$.
4. The CS is observed during quiet conditions, i.e., the $x$ component $v_{\mathrm{p} x}$ of the proton bulk velocity, is small during the CS crossing, $\left|v_{\mathrm{p} x}\right|<150 \mathrm{~km} \mathrm{~s}^{-1}$.

\section{CS parameters}

In this section we present the statistics of the following CS parameters: the characteristic current density, magnetic field magnitudes, the CS thickness and particle adiabaticity parameters. The properties of strongly titled CSs are compared with those of horizontal CSs reported in previous studies (see, e.g., Runov et al., 2005, 2006; Artemyev et al., 2010).

The comparison of curlometer, $\left\langle j_{\mathrm{cm}}\right\rangle$, and timing currents, $\left\langle j_{\text {tim }}\right\rangle$, is presented in Fig. 4a. This figure does not include very intense CSs22, 23 with $\left\langle j_{\mathrm{tim}}\right\rangle \sim 50 \mathrm{nA} \mathrm{m}^{-2}$ and $\left\langle j_{\mathrm{cm}}\right\rangle \sim$ $30 \mathrm{nA} \mathrm{m}^{-2}$. Black points correspond to the CSs observed in 2001, 2002 and 2004, while orange points correspond to the CSs observed in 2003. The curlometer and timing currents are generally consistent for the CSs with $\left\langle j_{\text {tim }}\right\rangle<8 \mathrm{nA} \mathrm{m}^{-2}$. For more intense CSs, i.e., with $\left\langle j_{\mathrm{tim}}\right\rangle>8 \mathrm{nA} \mathrm{m}^{-2}$, the timing current exceeds the curlometer one. This occurs because the curlometer technique underestimates the current density for intense (or, equivalently, thin) CSs due to the substantial spacecraft separation.

Figure $4 \mathrm{~b}$ confirms that the difference between $\left\langle j_{\mathrm{cm}}\right\rangle$ and $\left\langle j_{\text {tim }}\right\rangle$ is larger for the CSs, whose thickness $L$ is smaller than (or comparable to) the average spacecraft separation $\Delta R$. The correlation coefficient, $r$, between $\left(\left\langle j_{\mathrm{tim}}\right\rangle-\left\langle j_{\mathrm{cm}}\right\rangle\right) /\left\langle j_{\mathrm{cm}}\right\rangle$ and $\log _{10}(L / \Delta R)$ is 0.7 . The average separation $\Delta R$ between spacecraft was $2000 \mathrm{~km}$ in 2001, $3600 \mathrm{~km}$ in 2002, $230 \mathrm{~km}$ in 2003 and $1000 \mathrm{~km}$ in 2004. As a result, for the CSs observed in 2003, current densities $\left\langle j_{\mathrm{cm}}\right\rangle$ and $\left\langle j_{\text {tim }}\right\rangle$ are very close to each other. We conclude that for CSs from our data set the timing technique provides a better estimate of the current density than the curlometer technique, since it is not affected by the finite separation between spacecraft. In the following analysis the curlometer current is used only to estimate the relation between current density components parallel and perpendicular to the magnetic field. We point out that the characteristic current densities for strongly tilted CSs are comparable to those observed for horizontal CSs (Runov et al., 2006), i.e. the current density is generally smaller than $15 \mathrm{nA} \mathrm{m}^{-2}$ (Fig. 4a).

Figure $4 \mathrm{c}$ presents the comparison of proton and electron current densities $\left\langle j_{\mathrm{pm}}\right\rangle$ and $\left\langle j_{\mathrm{em}}\right\rangle$. The proton current exceeds the electron current only in seven CSs. We could conclude that strongly tilted CSs are statistically electrondominated, i.e., $\left\langle j_{\mathrm{em}}\right\rangle>\left\langle j_{\mathrm{pm}}\right\rangle$. However, Fig. $4 \mathrm{~d}$ shows that the sum of proton and electron currents $\left\langle j_{\mathrm{em}}\right\rangle+\left\langle j_{\mathrm{pm}}\right\rangle$ does not properly agree with the timing current $\left\langle j_{\text {tim }}\right\rangle$; the correlation coefficient, $r$, between $\left\langle j_{\mathrm{em}}\right\rangle+\left\langle j_{\mathrm{pm}}\right\rangle$ and $\left\langle j_{\mathrm{tim}}\right\rangle$ is 0.2 , and $0.7\left\langle j_{\text {tim }}\right\rangle<\left\langle j_{\mathrm{pm}}\right\rangle+\left\langle j_{\mathrm{em}}\right\rangle<1.3\left\langle j_{\text {tim }}\right\rangle$ only in $11 \mathrm{CSs}$. The same discrepancy has been previously observed for horizontal CSs (see, e.g., Fig. 3 in Asano et al., 2003, and Fig. 1 in 

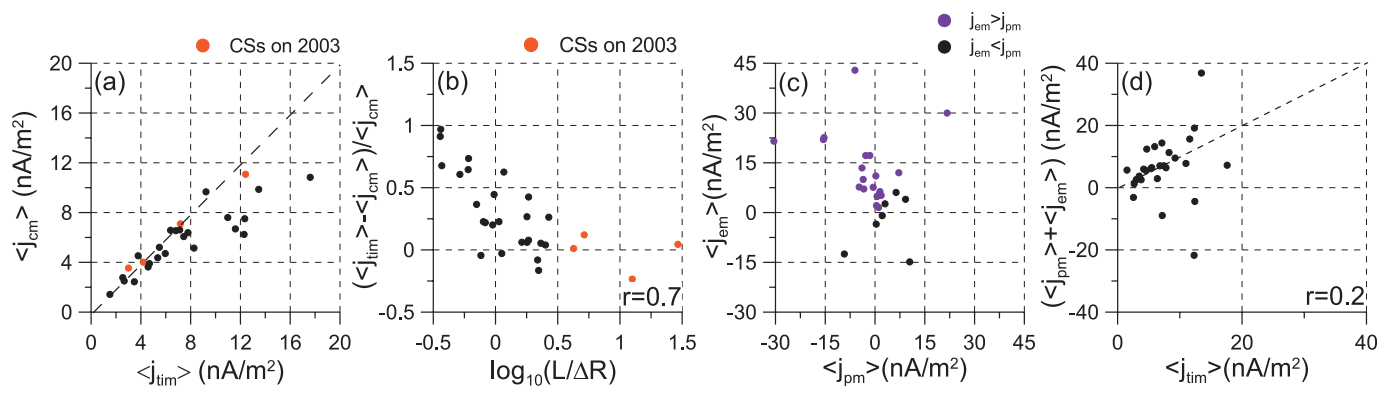

Fig. 4. (a) The comparison of current densities $\left\langle j_{\mathrm{cm}}\right\rangle$ and $\left\langle j_{\mathrm{tim}}\right\rangle$ determined by curlometer and timing techniques. (b) The correlation between the difference of curlometer $\left\langle j_{\mathrm{cm}}\right\rangle$ and timing $\left\langle j_{\mathrm{tim}}\right\rangle$ currents and the ratio of the CS thickness $L$ and the average separation between spacecraft $\Delta R$. (c) The comparison of proton $\left\langle j_{\mathrm{pm}}\right\rangle$ and electron $\left\langle j_{\mathrm{em}}\right\rangle$ currents. (d) The comparison between the sum of particle currents $\left\langle j_{\mathrm{pm}}\right\rangle+\left\langle j_{\mathrm{em}}\right\rangle$ and the timing current $\left\langle j_{\mathrm{tim}}\right\rangle$. In panels (a) and (c) we do not show CSs22and23 with $j_{\text {tim }} \sim 50 \mathrm{nAm}^{-2}$.

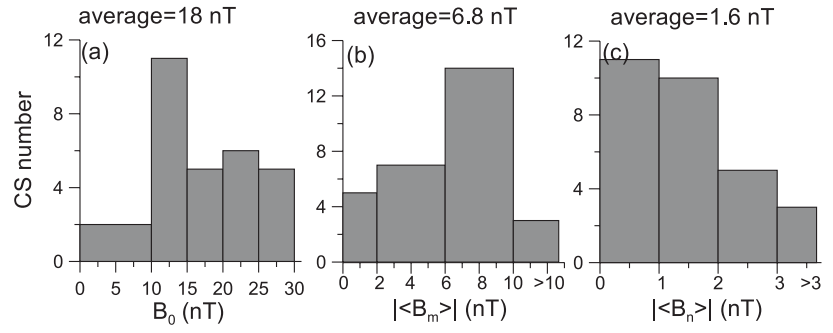

Fig. 5. Panel (a) shows the distribution of $B_{0}$, the value of the magnetic field $B_{l}$ at the CS boundary. Panels (b) and (c) present distributions of absolute values of perpendicular $B_{n}$ and shear $B_{m}$ components. The averaged values (over all $29 \mathrm{CSs}$ ) are shown at the top.

Zelenyi et al., 2010). Therefore we cannot always reliably determine the main current carriers based on estimates of proton and electron currents (see discussion in Sect. 5).

Figure 5 a presents the distribution of $B_{0}$, i.e., the value of $B_{l}$ at the CS boundary. The average value of $B_{0}$ is $18 \mathrm{nT}$. Similar values of $B_{0}$ are characteristic for horizontal CSs (Runov et al., 2005, 2006; Artemyev et al., 2010). Figure $5 \mathrm{~b}$ confirms that in strongly tilted CSs the shear (currentaligned) component $B_{m} \sim B_{z}$ is rather large (Petrukovich et al., 2006), and that the averaged (over $29 \mathrm{CSs}$ ) value of $\left|\left\langle B_{m}\right\rangle\right|$ is about $6.8 \mathrm{nT}$. The perpendicular component $B_{n}$ is generally smaller than $2 \mathrm{nT}$ and the averaged (over $29 \mathrm{CSs}$ ) value of $\left|\left\langle B_{n}\right\rangle\right|$ is about $1.6 \mathrm{nT}$ (Fig. 5c). Figure 6a presents the distribution of the ratio $\left|\left\langle B_{n}\right\rangle\right| /\left|\left\langle B_{m}\right\rangle\right|$. The perpendicular component is on average three times smaller than the currentaligned component.

Thus, the current in strongly tilted CSs has a significant field-aligned component near the CS neutral plane, as previously noticed by Shen et al. (2008). Moreover, Fig. 6b shows that $B_{m}$ can be comparable to $B_{0}$, on average $B_{m}$ is about $0.45 B_{0}$, so that the current density can have a significant field-aligned component even far from the neutral plane. Figure $2 f_{R}$ illustrates both of these conclusions for CS 29 .
Figure $6 \mathrm{c}$ presents the distribution of the ratio $\left|\left\langle j_{\|}\right\rangle\right| /\left\langle j_{\perp}\right\rangle$ of field-aligned and transverse currents for all CSs. On average, the field-aligned current is about two times larger than the transverse current.

Figure 7 presents the distribution of the CS thickness $L$ and shows that, generally, $L<3000 \mathrm{~km}$ and $L<10 \rho_{\mathrm{p}}\left(\rho_{\mathrm{p}, \mathrm{e}}\right.$ are characteristic proton and electron thermal gyroradii in the field $B_{0}$ ). Thus, thicknesses of strongly tilted and horizontal CSs are comparable (Runov et al., 2006). Particle dynamics in the CS with $B_{m} \neq 0$ is defined by the dimensionless adiabaticity parameter (Büchner and Zelenyi, 1989; Buechner and Zelenyi, 1991):

$\kappa_{\mathrm{p}, \mathrm{e}}=\frac{B_{n}}{B_{0}} \sqrt{\frac{L}{\rho_{\mathrm{p}, \mathrm{e}}}}\left(1+\left(\frac{B_{m}}{B_{n}}\right)^{2}\right)^{3 / 4}$.

Figure 8 a shows that in $85 \%$ of the CSs $\kappa_{\mathrm{p}}>0.5$ (due to large shear component $B_{m}$ ). By contrast, for horizontal CSs $\kappa_{\mathrm{p}}$ is smaller than 0.5 in about a half of the cases studied by Runov et al. (2006). Thus, protons cannot be considered in the quasi-adiabatic approximation $\left(\kappa_{\mathrm{p}} \ll 1\right)$ as in case of horizontal CSs (Zelenyi et al., 2011). The proton dynamics in strongly tilted CSs very likely becomes stochastic, $\kappa_{\mathrm{p}} \sim 0.5-3$, or protons are magnetized, $\kappa_{\mathrm{p}}>3$ (Büchner and Zelenyi, 1989). Figure $8 \mathrm{~b}$ shows that electrons are generally magnetized $\left(\kappa_{\mathrm{e}}>3\right)$ and hence can be considered in the frame of the magnetohydrodynamics (MHD) approximation.

\section{Electrostatic effects: Ohm's law}

In this section we discuss the distribution of the electric field $E_{n}$ (Fig. $2 \mathrm{~d}_{\mathrm{R}}$ ) from the theoretical point of view. In $1 \mathrm{D}$ planar CS all CS parameters depend on the distance, $r_{n}$, from the neutral plane along the normal vector $\boldsymbol{n}$. We write the Ohm's law for electrons, i.e., the MHD stress balance along 


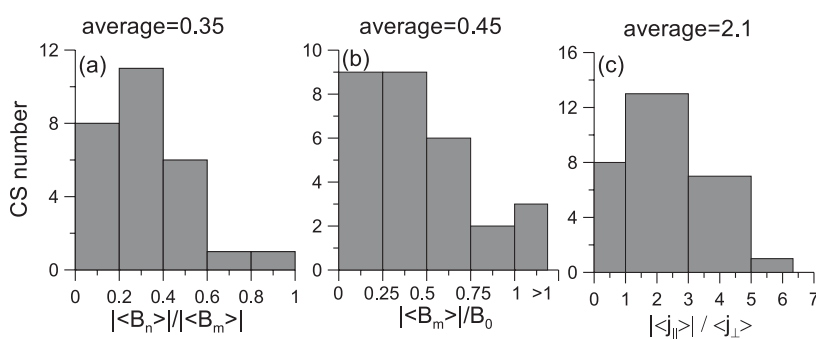

Fig. 6. Panels present distributions of absolute values of ratios $B_{n} / B_{m}$ (a), $B_{m} / B_{0}$ (b) and $\left\langle j_{\|}\right\rangle /\left\langle j_{\perp}\right\rangle$ (c). The averaged values (over all $29 \mathrm{CSs}$ ) are shown at the top.
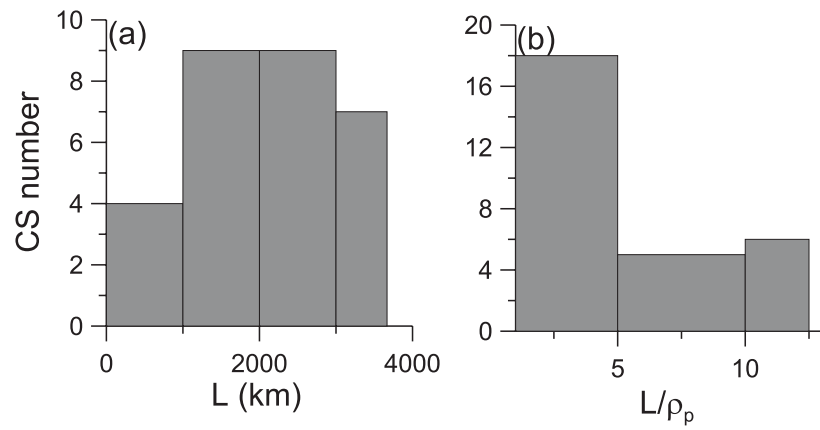

Fig. 7. The distribution of the thickness of strongly tilted CSs in absolute units (a) and in the units of proton thermal gyroradii (b).

the normal vector (Shkarofsky et al., 1966):

$e n_{\mathrm{e}} E_{n}=-\frac{\partial p_{\mathrm{e}}}{\partial r_{n}}-j_{\mathrm{em}} B_{l}-e n_{\mathrm{e}} v_{\mathrm{el}} B_{m}$,

where $v_{\mathrm{el}}$ is the electron earthward (tailward) bulk velocity. $E_{n}$ is the sum of the polarization (the first two terms on the right-hand side) and convection (the third term) electric fields. Let us consider the polarization electric field near the neutral plane. According to Zelenyi et al. (2010) the profile of the electron pressure can be approximated by the parabolic function of the magnetic field $B_{l}$, i.e., $p_{\mathrm{e}}=p_{0}(1-$ $\left.a B_{l}^{2} / B_{\mathrm{ext}}^{2}\right)$, where $p_{0}$ and $a$ are constants. Therefore in the neutral plane we have $\partial p_{\mathrm{e}} / \partial r_{n} \sim 0$. Taking into account that $j_{\mathrm{em}} B_{l} \sim 0$ in the neutral plane as well, we conclude that the polarization field drops to zero therein. As a result, the convection field $E_{n 0}$ can be determined as a value of $E_{n}$ at the CS neutral plane, while the polarization field is $E_{n}-E_{n 0}$.

The electrostatic potential $\phi$ of the polarization electric field is the sum of two terms, $\phi=\phi_{0}+\phi_{\chi}$, where $\phi_{0}$ is due to the electron pressure gradient, while $\phi_{\chi}$ is due to $\boldsymbol{j} \times \boldsymbol{B}$ force:

$\phi\left(r_{n}\right)=\phi_{0}+\phi_{\chi}=\int_{0}^{r_{n}} \frac{1}{e n_{\mathrm{e}}} \frac{\partial p_{\mathrm{e}}}{\partial r_{n}} \mathrm{~d} r_{n}+\frac{1}{e} \int_{0}^{r_{n}} \frac{1}{n_{\mathrm{e}}} j_{\mathrm{em}} B_{l} \mathrm{~d} r_{n}$.

Since the plasma density does not substantially vary across the CS (McComas et al., 1986; Runov et al., 2006; Artemyev
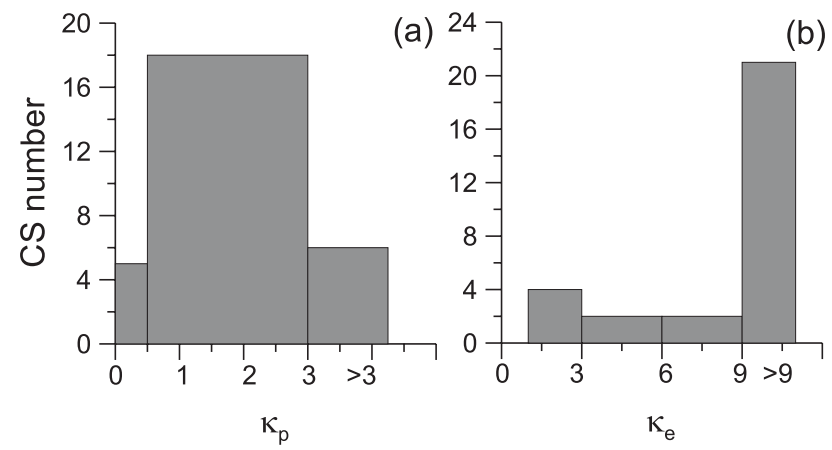

Fig. 8. Distributions of proton (a) and electron (b) adiabaticity parameters.

et al., 2010), we neglect its variation and obtain the following estimate: $\phi_{0} \sim p_{\mathrm{e}} / e n_{\mathrm{e}}+\mathrm{const} \sim-\left(p_{0} a / e n_{\mathrm{e}}\right) B_{l}^{2} / B_{\mathrm{ext}}^{2}$. Thus, $\phi_{0}$ has a parabolic profile with a maximum in the neutral plane for $a>0$ and a minimum for $a<0$. In fact, the electron pressure usually has a maximum in the neutral plane, so that $a>0$ and $\phi_{0}$ has a maximum. We conclude that for sufficiently small $j_{\mathrm{em}}$ (so that $\phi_{\chi} \ll \phi_{0}$ ) the polarization potential $\phi$ has a maximum in the neutral plane.

Now we investigate the role of the potential $\phi_{\chi}$. We denote the fraction of the total current density carried by electrons by $\chi$, so that $j_{\mathrm{em}}=\mu_{0}^{-1} \chi\left(r_{n}\right) \partial B_{l} / \partial r_{n}$. Then the polarization potential $\phi$ is determined as

$\phi\left(r_{n}\right)=\phi_{0}\left(r_{n}\right)+\int_{0}^{r_{n}} \frac{\chi\left(r_{n}\right)}{e n_{\mathrm{e}}} \frac{\partial}{\partial r_{n}}\left(\frac{B_{l}^{2}}{2 \mu_{0}}\right) \mathrm{d} r_{n}$.

Let us assume that $\chi\left(r_{n}\right)$ does not significantly vary across the CS, i.e., $\chi\left(r_{n}\right) \sim$ const. Neglecting the electron density variation in Eq. (4), we obtain the following estimate:

$e \phi\left(r_{n}\right) \approx-a \frac{p_{0}}{n_{\mathrm{e}}} \frac{B_{l}^{2}}{B_{\mathrm{ext}}^{2}}+\chi T_{\mathrm{p}} \frac{B_{l}^{2}}{B_{\mathrm{ext}}^{2}} \sim\left(\chi T_{\mathrm{p}}-a T_{\mathrm{e}}\right) \frac{B_{l}^{2}}{B_{\mathrm{ext}}^{2}}$,

where we have taken into account that $B_{\mathrm{ext}}^{2}=2 \mu_{0} n_{\mathrm{e}}\left(T_{\mathrm{p}}+\right.$ $\left.T_{\mathrm{e}}\right)+B_{m}^{2}+B_{n}^{2} \sim 8 \pi n_{\mathrm{e}} T_{\mathrm{p}}$, since $T_{\mathrm{p}} / T_{\mathrm{e}} \sim 4-7$ (Baumjohann et al., 1989; Artemyev et al., 2011). The potential $\phi$ has a parabolic profile with a maximum in the neutral plane for $\chi<a T_{\mathrm{e}} / T_{\mathrm{p}}$ and a minimum for $\chi>a T_{\mathrm{e}} / T_{\mathrm{p}}$. Since $T_{\mathrm{p}} / T_{\mathrm{e}} \sim$ $4-7$ and the parameter $a$ is of the order of unity, the polarization potential has minimum in the neutral plane for $\chi$ larger than $\sim 0.25$. Finally, we note that in reality the parameter $\chi$ can vary across the CS, so that in general case the second integral in Eq. (4) cannot be estimated straightforwardly.

\section{The observed profiles of electrostatic field}

In this section we determine the electric field and the corresponding electrostatic potential, which are due to the plasma 

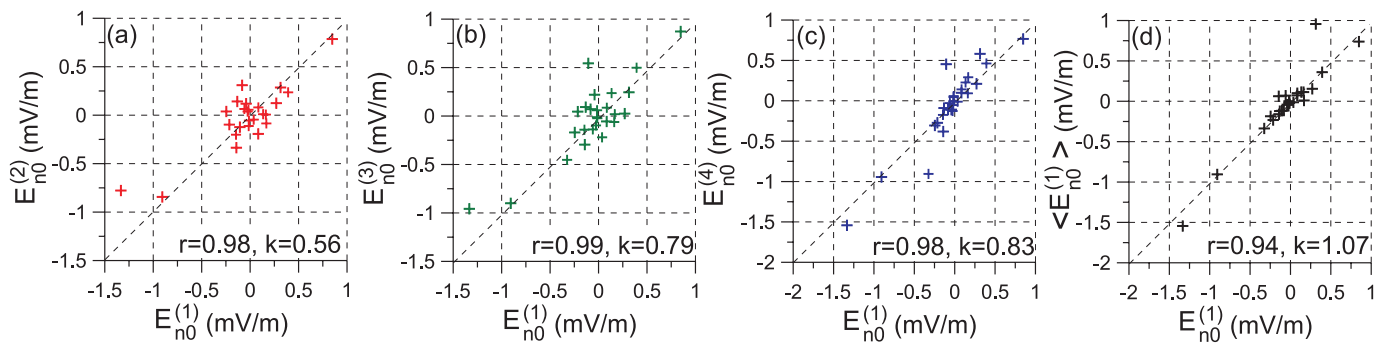

Fig. 9. Panels (a)-(c) present the comparison between convection electric fields $E_{n 0}^{(\alpha)}$ determined by use of electric fields measured at different spacecraft. Panel (d) presents the comparison between the convection field $E_{n 0}^{(1)}$ (the value of $E_{n}^{(1)}$ at $\left.B_{l}^{(1)}=0\right)$ and the averaged value of $E_{n}^{(1)}$ across the CS central region $\left(\left|B_{l}^{(1)}\right|<5 \mathrm{nT}\right)$.

polarization. The comparison of observed and theoretical potentials allows us also to draw the conclusion about the electron current density magnitude.

The convection field can be estimated as a value of measured electric fields $E_{n}^{(\alpha)}$ at the neutral plane (denoted as $\left.E_{n 0}^{(\alpha)}\right)$. Fig. 9 shows that $E_{n 0}^{(1)}$ correlates well with $E_{n 0}^{(2),(3),(4)}$ (correlation coefficients $r$ and slopes $k$ are presented in Fig. 9), so that four spacecraft observe generally the same convection field. We have also calculated averaged values $\left\langle E_{n}^{(\alpha)}\right\rangle$ over the CS central region $\left(\left|B_{l}^{(\alpha)}\right|<5 \mathrm{nT}\right)$. For example, Fig. 9d presents a good correlation between $\left\langle E_{n}^{(1)}\right\rangle$ and $E_{n 0}^{(1)}(r=0.94, k=1.07)$. We conclude that the estimate of the convection field as a value of $E_{n}^{(\alpha)}$ at the neutral plane is reliable.

The convection field can be now subtracted from $E_{n}^{(\alpha)}$ to determine the polarization field. Figure 10 presents profiles of the polarization field $E_{n}^{(\alpha)}-E_{n 0}^{(\alpha)}$ across the CS. There are 27 panels, since the electric field was not measured for CSs 2 and 12. Several panels include less than four profiles, because some spacecraft did not measure the electric field during corresponding CS crossings. Figure 10 shows that maximal values of the electric field are within the range of $0.2 \mathrm{mV} \mathrm{m}^{-1}$ (see, e.g., CS 21) to $8 \mathrm{mV} \mathrm{m}^{-1}$ (CS 1). Since we know the CS flapping velocity, we can determine the profile of the polarization potential $\phi^{(\alpha)}$ :

$\phi^{(\alpha)}\left(r_{n}\right)=-\int_{t_{0 \alpha}}^{t}\left(E_{n}^{(\alpha)}-E_{n 0}^{(\alpha)}\right)\left\langle V_{n}\right\rangle \mathrm{d} t$,

where $t_{0 \alpha}$ is the moment of the neutral plane crossing by spacecraft $C \alpha$, so that $\phi^{(\alpha)}=0$ at the neutral plane. In Eq. (6) we have used the averaged velocity $\left\langle V_{n}\right\rangle$, since $V_{n}$ does not significantly vary across the CS. Figure 11 presents profiles of the polarization potential. Drops of the potential between the neutral plane and the CS boundary are within the range of $200 \mathrm{~V}$ (e.g., CSs8) to $12 \mathrm{kV}$ (CS 1).

Each panel in Fig. 11 is marked by the label A or B. Set A includes $15 \mathrm{CSs}$, where profiles of the polarization potential observed at four spacecraft are similar and have minima in the neutral plane. The other CSs are referred to as set B and are discussed in the end of this section. Now we focus on the analysis of the polarization potentials observed for the CSs of set $\mathrm{A}$.

According to Eq. (3) the polarization potential is the sum of two terms, $\phi_{0}$ and $\phi_{\chi}$. The potential $\phi_{0}$ can be calculated in a similar manner to $\phi^{(\alpha)}$ :

$\phi_{0}=\int_{t_{0 \alpha}}^{t} \frac{1}{n_{\mathrm{e}}} \frac{\partial p_{\mathrm{e}}}{\partial r_{n}}\left\langle V_{n}\right\rangle \mathrm{d} t$.

Figure 11 shows that the potential $\phi_{0}$ (presented by dashed curves) has maximum in the neutral plane for all CSs of set A. Therefore the profiles of $\phi^{(\alpha)}$ and $\phi_{0}$ are qualitatively different. For example, for CS $29 \phi^{(\alpha)}$ have minima in the neutral plane, while $\phi_{0}$ has a maximum therein. Thus, the polarization potential in principle cannot be described by the first term on the right-hand side of Eq. (3), so the second term should be taken into account.

The potential $\phi_{\chi}$ depends on the parameter $\chi\left(r_{n}\right)$, whose profile across the CS is unknown. Therefore some assumptions should be done to determine the profile of $\phi_{\chi}$. Lets suppose that $\chi$ does not vary across the CS. Then the theoretical potential $\phi$ can be determined as (see Eq. 4 ):

$\phi=\phi_{0}+\chi \int_{t_{0 \alpha}}^{t} \frac{1}{2 \mu_{0} e n_{\mathrm{e}}} \frac{\partial B_{l}^{2}}{\partial r_{n}}\left\langle V_{n}\right\rangle \mathrm{d} t$.

For each CS one can accurately tune the parameter $\chi$ so as to reach an agreement between observed $\phi^{(\alpha)}$ and theoretical $\phi$ potentials. We follow a less intricate approach and assume $\chi=1$ for all CSs. Figure 11 shows that this assumption results in theoretical potentials whose profiles are similar to profiles of observed potentials. For example, for CS 29 both the theoretical and observed potentials have minimum in the neutral plane. We do not introduce any quantitative criteria of the agreement between $\phi^{(\alpha)}$ and $\phi$, although in the majority of the CSs profiles of theoretical and observed potentials are actually close (see, e.g., CSs 1, 4, 8, 10, 11, 15, 16, 17, 27, and 29). We conclude that the polarization potential observed 

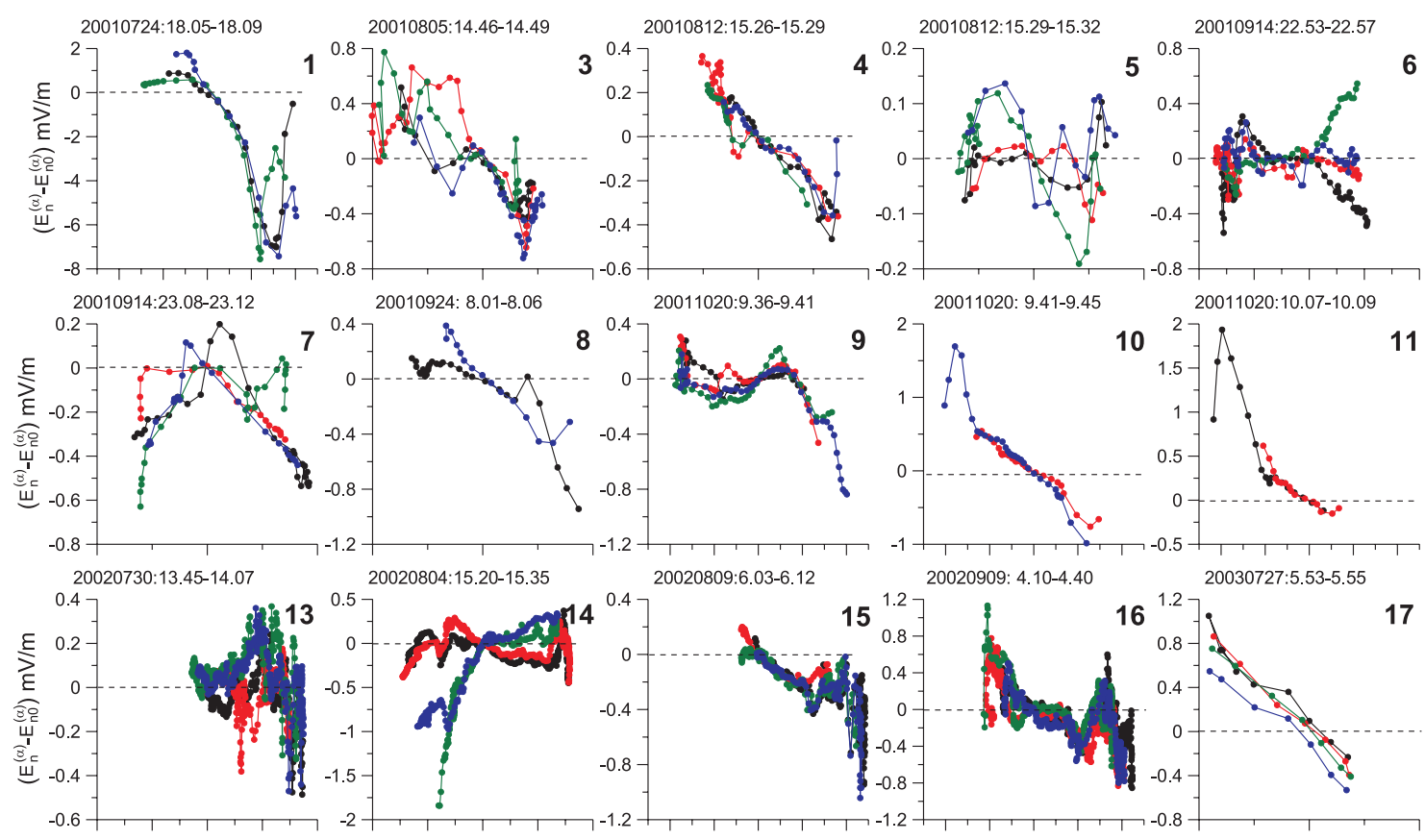

20020909: 4.10-4.40

\section{"}
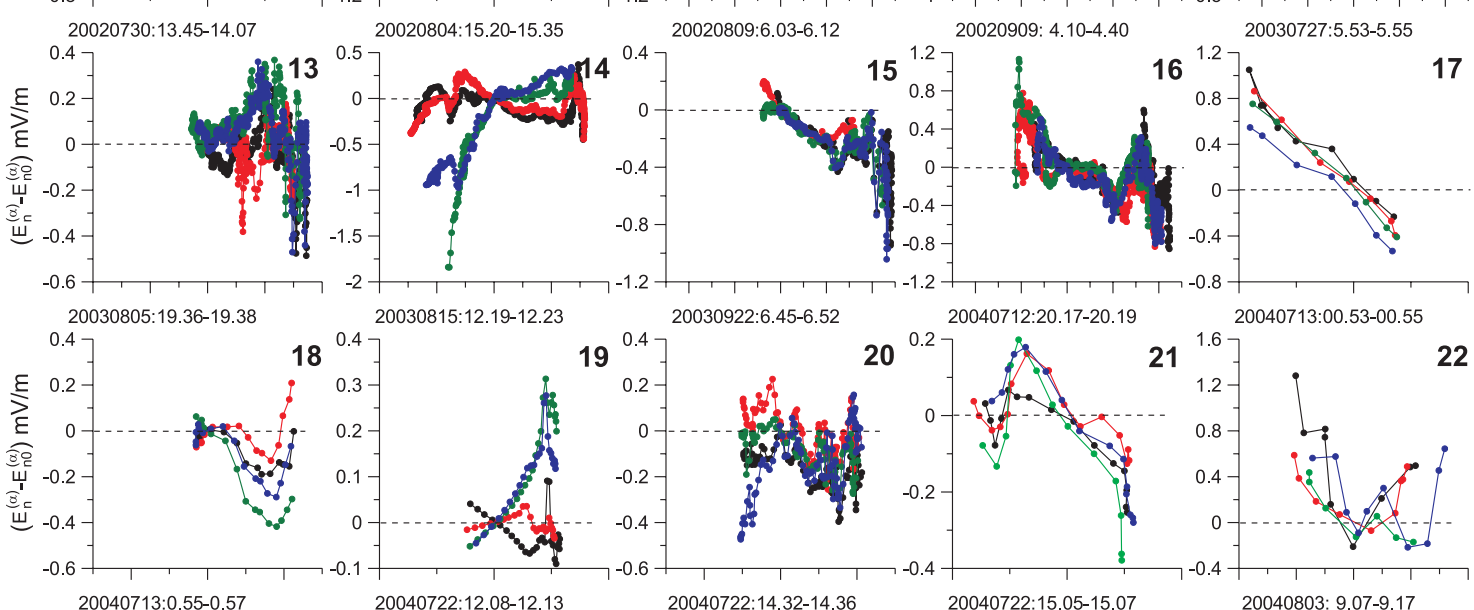

17
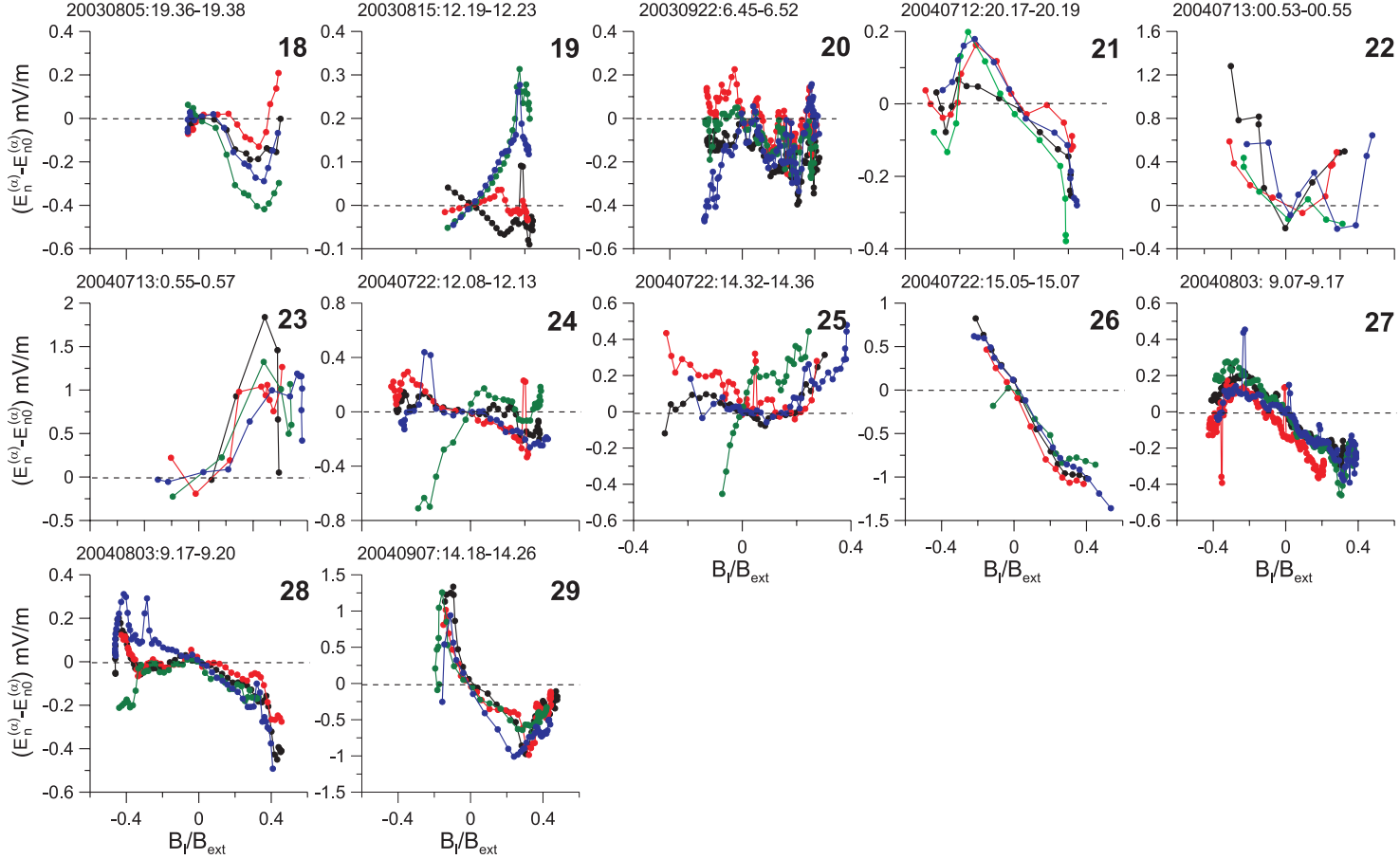

Fig. 10. Profiles of electric fields $E_{n}^{(\alpha)}-E_{n 0}^{(\alpha)}$. Black, red, green and blue curves correspond to the measurements of C1-C4, respectively. Central ticks at horizontal axes of each panel correspond to $B_{l}=0$, while one large tick interval is equal to 0.4.

for the CSs of set A can be explained under assumption that the significant fraction of the total current density is carried by electrons.

Finally, we discuss the CSs of set B. For CSs 7, 9, 20, and 22 , profiles of the potential observed at four spacecraft are similar, although they have neither minima nor maxima in the neutral plane. Figure 11 shows that observed profiles and the theoretical profile (obtained using $\chi=1$ ) are similar only for CS 20. We have found that the potentials observed for CSs 7, 9, and 22 cannot be explained under the assumption $\chi\left(r_{n}\right) \sim$ const. For these CSs, the parameter $\chi$ does likely vary across the CS.

For CS 23, potentials observed at four spacecraft are similar and have maxima in the neutral plane. Potential $\phi^{(\alpha)}$ 

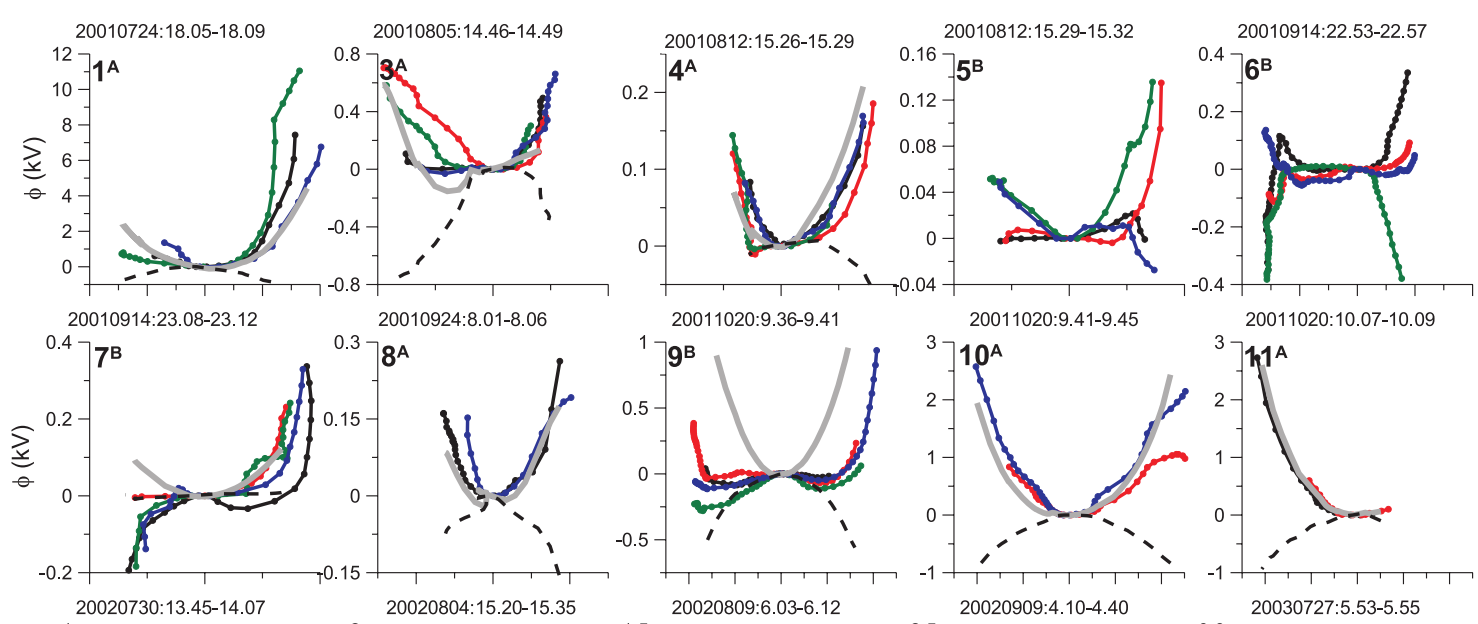

20011020:10.07-10.09
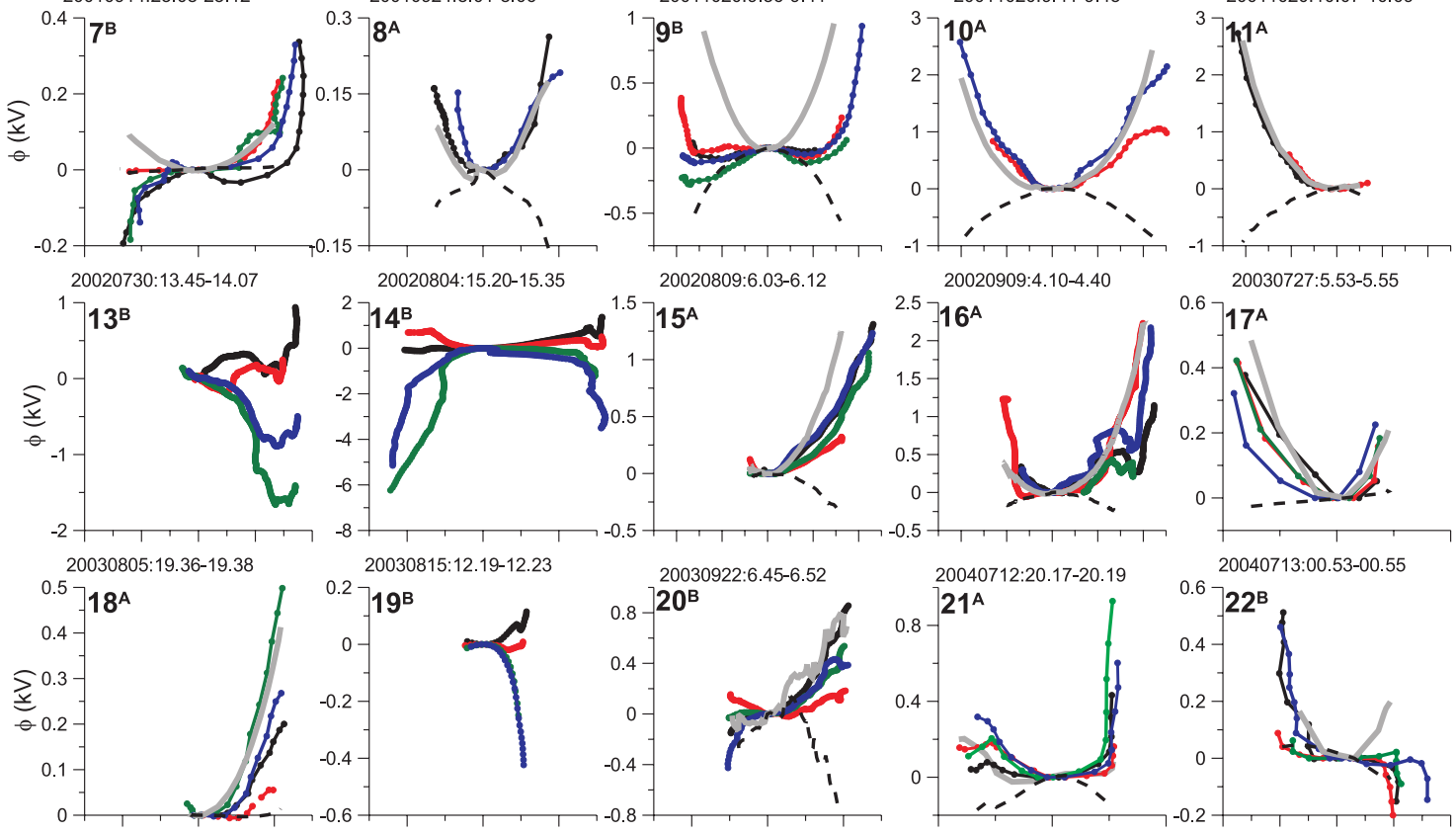

20030727:5.53-5.55
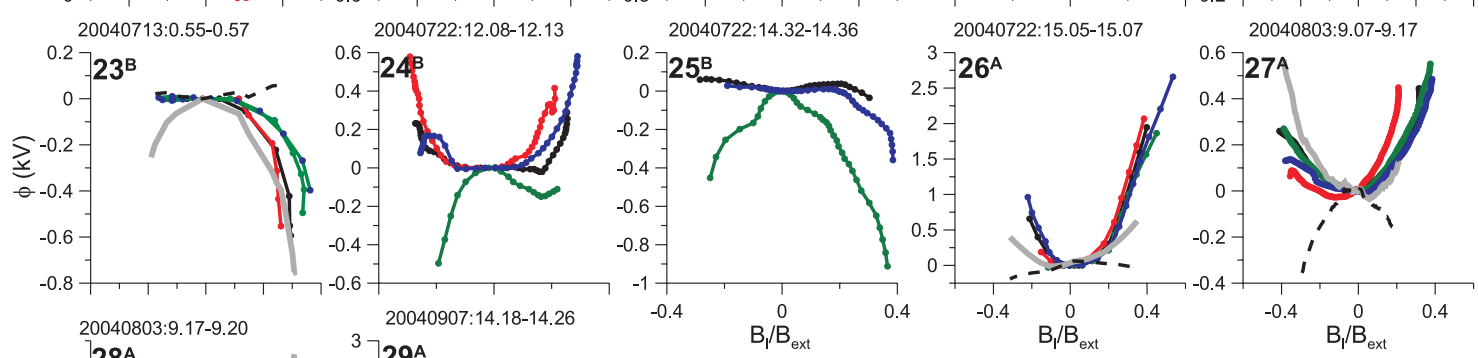

$0.677^{\mathrm{A}}$
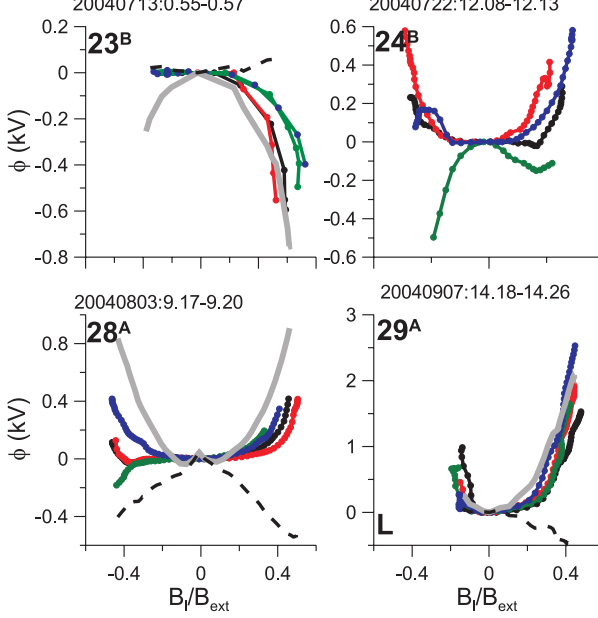

3 29A

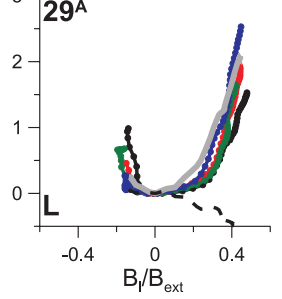

Fig. 11. Electrostatic potentials corresponding to electric fields $E_{n}^{(\alpha)}-E_{n 0}^{(\alpha)}$ (black, red, green and blue curves correspond to C1, C2, C3, and $\mathrm{C} 4$, respectively). Black dashed curves present profiles of theoretical potentials, which are due to the electron pressure gradient only. The gray curves present profiles of theoretical potentials derived from the Ohm's law under the assumption that the electron current density is comparable to the total current density. Central ticks on horizontal axes correspond to $B_{l}=0$, while one large tick interval is equal to 0.4 .

cannot be due to the electron pressure gradient, since for CS 23 , the potential $\phi_{0}$ has a minimum in the neutral plane. On the other hand, these potentials can be explained under the assumption $\chi=-1$ (see Fig. 11), implying that the electron current density is negative, while its magnitude is equal to the total current density. The proton current should be then positive and two times larger than the total current density. However, this assumption seems to be rather unrealistic. It is also not supported by observed particle currents, for which CS 23 is in good agreement with the timing current (Table 1). 
Thus, the potential observed for CS 23 can be explained only under rather unrealistic conditions.

In other CSs of set B, the profiles of the polarization potential observed at four spacecraft substantially differ from each other (see, e.g., CSs 5, 6, 13, 14, 19, 24, and 25). The discrepancy may be due to the significant electric field variation in space (or time) on the scale of spacecraft separation (or the scale of CS crossing). The other reason may be that the perpendicular electric field $E_{n}$ is calculated using only $E_{y}$, while $E_{x}$ and $E_{z}$ are neglected. The potentials observed for these CSs in principle cannot be interpreted in the frame of our model.

\section{Discussion}

For strongly tilted CSs, the characteristic current density, magnetic field at the CS boundary, and CS thickness are found to be similar to those for horizontal CSs. In contrast to horizontal CSs, strongly tilted CSs are characterized by the rather large shear magnetic field component and the significant field-aligned current. Strongly tilted CSs provide a unique opportunity to study the distribution of the electric field, which is due to the plasma polarization. The polarization potentials observed for $15 \mathrm{CSs}$ of set $\mathrm{A}$ and one CS of set $\mathrm{B}$ suggest that the electron current density is comparable to the total current density.

Analyzing the structure of strongly tilted CSs, we have encountered several problems. First, there is a disagreement between the sum of particle currents $j_{\mathrm{me}}+j_{\mathrm{mp}}$ and the timing current $j_{\text {tim }}$. Although we clearly observe the dominance of the electron current in the majority of the CSs, any conclusions based on particle currents should be treated with caution. In fact, the same discrepancy between $j_{\mathrm{me}}+j_{\mathrm{mp}}$ and $j_{\text {tim }}$ has been observed by Asano et al. (2003) using the Geotail data. This discrepancy may be due to the measurement uncertainties or substantial natural time (or space) variability of the electron current. This will be the focus of future studies. The other problem is that electron and proton densities provided by Cluster can differ up to $40 \%$. We have used the electron density, but the use of the proton density does not influence any of our conclusions.

We have calculated the proton current density using proton density and bulk velocity provided by the CODIF (Composition and Distribution Function) instrument (with upper cutoff energy $E_{0} \approx 40 \mathrm{keV}$ ). Because we have not taken into account high-energy protons, the proton current density could be underestimated. This error can be a cause of the inconsistency between particle and timing currents. The errors of proton moments (density, velocity, temperature) caused by CODIF cut-off energy depend on (1) how heavy the energetic tail of the proton distribution function is; (2) the relation between the proton temperature and the cut-off energy.

Statistical studies show that proton distribution function has energetic tails; these can be described by $\kappa$-distribution with $\kappa>3.5$ (see, e.g., Christon et al., 1989; Haaland et al., 2010). Kissinger et al. (2012) have presented the statistical study of the proton temperature magnitude within the plasma sheet using THEMIS (Time History of Events and Macroscale Interactions During Substorms) data including measurements of high-energy protons (upper energy limit$6 \mathrm{MeV})$. They have found that in quiet periods, the proton temperature can hardly exceed $10 \mathrm{keV}$. We point out that for CSs from our data set, the proton temperature (given by CODIF) also does not exceed $10 \mathrm{keV}$.

Let us assume that for CSs from our data set, energetic tails of proton distribution functions can be described by $\kappa$ distribution with $\kappa=3.5$. The maximum proton temperature is the quarter of the CODIF cut-off energy $E_{0} \approx 40 \mathrm{keV}$. We have found (not shown here) that in this worst case, CODIF underestimates the density by about $20 \%$, the velocity by about $40 \%$ and the proton temperature by no more than a factor of 2.5. Therefore in the worst case, the proton current density can be underestimated by $50 \%$. Such an error can be the reason for the inconsistency between particle and timing currents. This error should be accurately estimated for each CS crossing and requires a separate study. At the same time we note that the inconsistency may be due to the inaccuracy of the electron current as well. In the present study we have not used particle currents, so that this problem does not affect our conclusions.

The underestimate of the proton temperature also does not significantly influence our conclusions. We have used CODIF temperature to estimate the proton thermal gyroradius $\left(\propto T_{\mathrm{p}}^{1 / 2}\right)$ and the proton adiabaticity parameter $(\propto$ $\left.T_{\mathrm{p}}^{-1 / 4}\right)$. Therefore the proton gyroradius can be underestimated by a factor of $\sim 1.6$, while the adiabaticity parameter can be overestimated by a factor of $\sim 1.25$. These uncertainties are not critical for our conclusions (see conclusions 1 and 3 in the next section). Finally, we note that the adiabaticity parameter $\kappa_{\mathrm{p}}$ has been estimated for thermal protons. For energetic protons the adiabaticity parameter is substantially smaller. Such protons can move along "Speiser" orbits (Speiser, 1965) and carry some portion of the total current (see, e.g., Lyons and Speiser, 1985). The estimate of their contribution requires a separate study. On the other hand, we point out that in CSs of class A their current is not large, since most of the current should be carried by electrons.

In Sect. 4 we implicitly indicated that the wavy deformation $z=z_{0}(y / \lambda)$ propagates along the $y$ axis with the phase velocity $v_{0}$. The corresponding induction electric field $\sim v_{0}\left[\boldsymbol{e}_{y}, \boldsymbol{B}\right] / c$ does not have the component along the $y$ axis (or, equivalently, along the normal vector $\boldsymbol{n}$ ). Therefore this component is absent in Eq. (2) for $E_{n}$. In fact, the phase velocity of the wavy deformation can have $x$ and $z$ components, while the perpendicular electric field $E_{n}$ and the polarization field $E_{n}-E_{n 0}$ can include some part of the induction field. This induction field cannot be distinguished from $E_{n}$, since $x$ and $z$ components of the phase velocity cannot be determined 
using Cluster measurements. On the other hand, the general agreement between theoretical and observed potentials for $16 \mathrm{CSs}$ shows that the induction field contained in $E_{n}-E_{n 0}$ is likely smaller than the polarization field.

\section{Conclusions}

We have studied properties of strongly tilted CSs using a data set of 29 CS crossings. Our conclusions are summarized below:

1. Strongly tilted CSs are in many respects similar to horizontal CSs: the current density is generally smaller than $\sim 15 \mathrm{nA} \mathrm{m}^{-2}$, the magnetic field $B_{0}$ is on average $\sim 18 \mathrm{nT}$ and the CS thickness is generally smaller than 10 proton gyroradii or $3000 \mathrm{~km}$.

2. We have confirmed that strongly tilted CSs are characterized by a rather large shear (current-aligned) magnetic field component $(\sim 6.8 \mathrm{nT})$ and a substantially smaller perpendicular magnetic field component ( 1.6 nT).

3. The current density has a significant field-aligned component as previously noted by Shen et al. (2008). We have found that the field-aligned current is on average two times larger than the transverse current.

4. The adiabaticity parameter for thermal protons, $\kappa_{\mathrm{p}}$, is larger than 0.5 in $85 \%$ of CSs. The proton dynamics is stochastic for 18 current sheets with $0.5<\kappa_{\mathrm{p}}<3$ and protons are magnetized for 6 sheets with $\kappa_{\mathrm{p}}>3$. Electrons are magnetized for all observed current sheets $\left(\kappa_{\mathrm{e}}>3\right)$ and can be considered in the frame of the MHD approximation.

5. Electric field measurements have been used to determine the perpendicular electric field. This electric field is generally due to the plasma polarization. The characteristic values of the polarization electric field are within the range of $0.2 \mathrm{mV} \mathrm{m}^{-1}$ to $8 \mathrm{mV} \mathrm{m}^{-1}$. The characteristic drops of the polarization potential between the neutral plane and the CS boundary are within the range of $200 \mathrm{~V}$ to $12 \mathrm{kV}$. For 16 of $27 \mathrm{CSs}$ the polarization potential profile can be explained by assuming that the electron current density is comparable to the total current density. For 15 of these CSs, the polarization potentials is symmetric with respect to the neutral plane and has a minimum therein.

Acknowledgements. The authors would like to acknowledge the Cluster Active Archive and the Cluster instrument teams, in particular FGM, CIS, PEACE, EFW, for excellent data. We would like to thank A. Runov for his database of crossings and Y. Khotyaintsev for useful discussion. The work of I. Y. Vasko was supported by the
RF Presidential Program for the State of Leading Schools (project NSh-248.2014.2.). The work of A. V. Artemyev was supported by the Russian Foundation for Basic Research (projects 14-02-01269). The work of R. Nakamura was supported by the Austrian Science Fund (FWF) I429-N16. I. Y. Vasko would like to acknowledge the hospitality of IWF, Graz, Austria.

Topical Editor I. A. Daglis thanks I. Dandouras and one anonymous referee for their help in evaluating this paper.

\section{References}

Artemyev, A. and Zelenyi, L.: Kinetic Structure of Current Sheets in the Earth Magnetotail, Space Sci. Rev., doi:10.1007/s11214012-9954-5, 2012.

Artemyev, A. V., Petrukovich, A. A., Nakamura, R., and Zelenyi, L. M.: Proton velocity distribution in thin current sheets: Cluster observations and theory of transient trajectories, J. Geophys. Res., 115, A12255, doi:10.1029/2010JA015702, 2010.

Artemyev, A. V., Baumjohann, W., Petrukovich, A. A., Nakamura, R., Dandouras, I., and Fazakerley, A.: Proton/electron temperature ratio in the magnetotail, Ann. Geophys., 29, 2253-2257, doi:10.5194/angeo-29-2253-2011, 2011.

Asano, Y., Mukai, T., Hoshino, M., Saito, Y., Hayakawa, H., and Nagai, T.: Evolution of the thin current sheet in a substorm observed by Geotail, J. Geophys. Res. Space Phys., 108, 1189, doi:10.1029/2002JA009785, 2003.

Balogh, A., Carr, C. M., Acuña, M. H., Dunlop, M. W., Beek, T. J., Brown, P., Fornacon, K.-H., Georgescu, E., Glassmeier, K.H., Harris, J., Musmann, G., Oddy, T., and Schwingenschuh, K.: The Cluster Magnetic Field Investigation: overview of in-flight performance and initial results, Ann. Geophys., 19, 1207-1217, doi:10.5194/angeo-19-1207-2001, 2001.

Baumjohann, W., Paschmann, G., and Cattell, C. A.: Average plasma properties in the central plasma sheet, J. Geophys. Res., 94, 6597-6606, doi:10.1029/JA094iA06p06597, 1989.

Baumjohann, W., Roux, A., Le Contel, O., Nakamura, R., Birn, J., Hoshino, M., Lui, A. T. Y., Owen, C. J., Sauvaud, J.-A., Vaivads, A., Fontaine, D., and Runov, A.: Dynamics of thin current sheets: Cluster observations, Ann. Geophys., 25, 13651389, doi:10.5194/angeo-25-1365-2007, 2007.

Birn, J., Artemyev, A. V., Baker, D. N., Echim, M., Hoshino, M., and Zelenyi, L. M.: Particle Acceleration in the Magnetotail and Aurora, Space Sci. Rev., 173, 49-102, doi:10.1007/s11214-0129874-4, 2012.

Büchner, J. and Zelenyi, L. M.: Regular and chaotic charged particle motion in magnetotaillike field reversals. I - Basic theory of trapped motion, J. Geophys. Res., 94, 11821-11842, doi:10.1029/JA094iA09p11821, 1989.

Buechner, J. and Zelenyi, L. M.: Regular and chaotic particle motion in sheared magnetic field reversals, Adv. Space Res., 11, 177-182, doi:10.1016/0273-1177(91)90030-N, 1991.

Chanteur, G.: Spatial Interpolation for Four Spacecraft: Theory, in: Analysis Methods for Multi-Spacecraft Data, edited by: Patschmann, G. and Daly, P. W., 349-370, 2000.

Christon, S. P., Williams, D. J., Mitchell, D. G., Frank, L. A., and Huang, C. Y.: Spectral characteristics of plasma sheet ion and electron populations during undisturbed geomagnetic conditions, J. Geophys. Res., 94, 13409-13424, doi:10.1029/JA094iA10p13409, 1989. 
Dunlop, M. W. and Woodward, T. I.: Multi-Spacecraft Discontinuity Analysis: Orientation and Motion, in: Analysis Methods for Multi-Spacecraft Data, edited by: Patschmann, G. and Daly, P. W., 271-306, 2000.

Gustafsson, G., André, M., Carozzi, T., Eriksson, A. I., Fälthammar, C.-G., Grard, R., Holmgren, G., Holtet, J. A., Ivchenko, N., Karlsson, T., Khotyaintsev, Y., Klimov, S., Laakso, H., Lindqvist, P.-A., Lybekk, B., Marklund, G., Mozer, F., Mursula, K., Pedersen, A., Popielawska, B., Savin, S., Stasiewicz, K., Tanskanen, P., Vaivads, A., and Wahlund, J.-E.: First results of electric field and density observations by Cluster EFW based on initial months of operation, Ann. Geophys., 19, 1219-1240, doi:10.5194/angeo19-1219-2001, 2001.

Haaland, S., Kronberg, E. A., Daly, P. W., Fränz, M., Degener, L., Georgescu, E., and Dandouras, I.: Spectral characteristics of protons in the Earth's plasmasheet: statistical results from Cluster CIS and RAPID, Ann. Geophys., 28, 1483-1498, doi:10.5194/angeo-28-1483-2010, 2010.

Harris, E.: On a plasma sheet separating regions of oppositely directed magnetic field, Nuovo Cimento, 23, 115-123, 1962.

Kissinger, J., McPherron, R. L., Hsu, T.-S., and Angelopoulos, V.: Diversion of plasma due to high pressure in the inner magnetosphere during steady magnetospheric convection, J. Geophys. Res. Space Phys., 117, A05206, doi:10.1029/2012JA017579, 2012.

Lyons, L. R. and Speiser, T. W.: Ohm's law for a current sheet, J. Geophys. Res., 90, 8543-8546, doi:10.1029/JA090iA09p08543, 1985.

McComas, D. J., Bame, S. J., Russell, C. T., and Elphic, R. C.: The near-earth cross-tail current sheet - Detailed ISEE 1 and 2 case studies, J. Geophys. Res., 91, 4287-4301, doi:10.1029/JA091iA04p04287, 1986.

Ness, N. F.: The Earth's Magnetic Tail, J. Geophys. Res., 70, 29893005, doi:10.1029/JZ070i013p02989, 1965.

Owen, C. J., Fazakerley, A. N., Carter, P. J., Coates, A. J., Krauklis, I. C., Szita, S., Taylor, M. G. G. T., Travnicek, P., Watson, G., Wilson, R. J., Balogh, A., and Dunlop, M. W.: Cluster PEACE observations of electrons during magnetospheric flux transfer events, Ann. Geophys., 19, 1509-1522, doi:10.5194/angeo-191509-2001, 2001.

Petrukovich, A. A., Baumjohann, W., Nakamura, R., Balogh, A., Mukai, T., Glassmeier, K.-H., Reme, H., and Klecker, B.: Plasma sheet structure during strongly northward IMF, J. Geophys. Res. Space Phys., 108, 1258, doi:10.1029/2002JA009738, 2003.

Petrukovich, A. A., Zhang, T. 1., Baumjohann, W., Nakamura, R., Runov, A., Balogh, A., and Carr, C.: Oscillatory magnetic flux tube slippage in the plasma sheet, Ann. Geophys., 24, 16951704, doi:10.5194/angeo-24-1695-2006, 2006.

Petrukovich, A. A., Baumjohann, W., Nakamura, R., and Runov, A.: Formation of current density profile in tilted current sheets, Ann. Geophys., 26, 3669-3676, doi:10.5194/angeo-26-36692008, 2008.

Rème, H., Aoustin, C., Bosqued, J. M., Dandouras, I., Lavraud, B., Sauvaud, J. A., Barthe, A., Bouyssou, J., Camus, Th., Coeur-Joly, O., Cros, A., Cuvilo, J., Ducay, F., Garbarowitz, Y., Medale, J. L., Penou, E., Perrier, H., Romefort, D., Rouzaud, J., Vallat, C., Alcaydé, D., Jacquey, C., Mazelle, C., d’Uston, C., Möbius, E., Kistler, L. M., Crocker, K., Granoff, M., Mouikis, C., Popecki, M., Vosbury, M., Klecker, B., Hovestadt, D., Kucharek, H.,
Kuenneth, E., Paschmann, G., Scholer, M., Sckopke, N., Seidenschwang, E., Carlson, C. W., Curtis, D. W., Ingraham, C., Lin, R. P., McFadden, J. P., Parks, G. K., Phan, T., Formisano, V., Amata, E., Bavassano-Cattaneo, M. B., Baldetti, P., Bruno, R., Chionchio, G., Di Lellis, A., Marcucci, M. F., Pallocchia, G., Korth, A., Daly, P. W., Graeve, B., Rosenbauer, H., Vasyliunas, V., McCarthy, M., Wilber, M., Eliasson, L., Lundin, R., Olsen, S., Shelley, E. G., Fuselier, S., Ghielmetti, A. G., Lennartsson, W., Escoubet, C. P., Balsiger, H., Friedel, R., Cao, J.-B., Kovrazhkin, R. A., Papamastorakis, I., Pellat, R., Scudder, J., and Sonnerup, B.: First multispacecraft ion measurements in and near the Earth's magnetosphere with the identical Cluster ion spectrometry (CIS) experiment, Ann. Geophys., 19, 1303-1354, doi:10.5194/angeo19-1303-2001, 2001.

Robert, P., Dunlop, M. W., Roux, A., and Chanteur, G.: Accuracy of Current Density Determination, in: Analysis Methods for MultiSpacecraft Data, edited by: Patschmann, G. and Daly, P. W., 395418, 2000.

Rong, Z. J., Shen, C., Petrukovich, A. A., Wan, W. X., and Liu, Z. X.: The analytic properties of the flapping current sheets in the earth magnetotail, Planet. Space Sci., 58, 1215-1229, doi:10.1016/j.pss.2010.04.016, 2010.

Rong, Z. J., Wan, W. X., Shen, C., Li, X., Dunlop, M. W., Petrukovich, A. A., Hau, L.-N., Zhang, T. L., Rème, H., Du, A. M., and Lucek, E.: Profile of strong magnetic field $\mathrm{B}_{y}$ component in magnetotail current sheets, J. Geophys. Res. Space Phys., 117, A06216, doi:10.1029/2011JA017402, 2012.

Runov, A., Sergeev, V. A., Baumjohann, W., Nakamura, R., Apatenkov, S., Asano, Y., Volwerk, M., Vörös, Z., Zhang, T. L., Petrukovich, A., Balogh, A., Sauvaud, J.-A., Klecker, B., and Rème, H.: Electric current and magnetic field geometry in flapping magnetotail current sheets, Ann. Geophys., 23, 1391-1403, doi:10.5194/angeo-23-1391-2005, 2005.

Runov, A., Sergeev, V. A., Nakamura, R., Baumjohann, W., Apatenkov, S., Asano, Y., Takada, T., Volwerk, M., Vörös, Z., Zhang, T. L., Sauvaud, J.-A., Rème, H., and Balogh, A.: Local structure of the magnetotail current sheet: 2001 Cluster observations, Ann. Geophys., 24, 247-262, doi:10.5194/angeo-24-2472006, 2006.

Schindler, K.: Physics of Space Plasma Activity, Cambridge University Press, doi:10.2277/0521858976, 2006.

Schindler, K., Birn, J., and Hesse, M.: Kinetic model of electric potentials in localized collisionless plasma structures under steady quasi-gyrotropic conditions, Phys. Plasmas, 19, 082904, doi:10.1063/1.4747162, 2012.

Schwartz, S.: Shock and Discontinuity Normlas, Mach Numbers, and Related Parameters, in: Analysis Methods for MultiSpacecraft Data, edited by: Patschmann, G. and Daly, P. W., 249270, 2000.

Sergeev, V., Runov, A., Baumjohann, W., Nakamura, R., Zhang, T. L., Balogh, A., Louarnd, P., Sauvaud, J., and Reme, H.: Orientation and propagation of current sheet oscillations, Geophys. Res. Lett., 31, 5807, doi:10.1029/2003GL019346, 2004.

Shen, C., Li, X., Dunlop, M., Liu, Z. X., Balogh, A., Baker, D. N., Hapgood, M., and Wang, X.: Analyses on the geometrical structure of magnetic field in the current sheet based on cluster measurements, J. Geophys. Res. Space Phys., 108, 1168, doi:10.1029/2002JA009612, 2003. 
Shen, C., Rong, Z. J., Li, X., Dunlop, M., Liu, Z. X., Malova, H. V., Lucek, E., and Carr, C.: Magnetic configurations of the tilted current sheets in magnetotail, Ann. Geophys., 26, 3525-3543, doi:10.5194/angeo-26-3525-2008, 2008.

Shkarofsky, I. P., Johnston, T. W., and Bachnynski, M. P.: The particle kinetic of plasmas, Addison-wesley Piblishing company, 1966.

Sonnerup, B. and Sheible, M.: Minimum and Maximum Variance Analysis, in: Analysis Methods for Multi-Spacecraft Data, edited by: Patschmann, G. and Daly, P. W., 185-220, 2000.

Speiser, T. W.: Particle Trajectories in Model Current Sheets, 1, Analytical Solutions, J. Geophys. Res., 70, 4219-4226, doi:10.1029/JZ070i017p04219, 1965.

Vallat, C., Dandouras, I., Dunlop, M., Balogh, A., Lucek, E., Parks, G. K., Wilber, M., Roelof, E. C., Chanteur, G., and Rème, H.: First current density measurements in the ring current region using simultaneous multi-spacecraft CLUSTER-FGM data, Ann. Geophys., 23, 1849-1865, doi:10.5194/angeo-23-18492005, 2005.

Zelenyi, L. M., Malova, H. V., Popov, V. Y., Delcourt, D., and Sharma, A. S.: Nonlinear equilibrium structure of thin currents sheets: influence of electron pressure anisotropy, Nonlinear Proc. Geoph., 11, 579-587, 2004.
Zelenyi, L. M., Artemyev, A. V., and Petrukovich, A. A.: Earthward electric field in the magnetotail: Cluster observations and theoretical estimates, Geophys. Res. Lett., 37, 6105, doi:10.1029/2009GL042099, 2010.

Zelenyi, L. M., Malova, H. V., Artemyev, A. V., Popov, V. Y., and Petrukovich, A. A.: Thin current sheets in collisionless plasma: Equilibrium structure, plasma instabilities, and particle acceleration, Plasma Phys. Rep., 37, 118-160, doi:10.1134/S1063780X1102005X, 2011.

Zhang, T. L., Baumjohann, W., Nakamura, R., Balogh, A., and Glassmeier, K.: A wavy twisted neutral sheet observed by CLUSTER, Geophys. Res. Lett., 29, 1899, doi:10.1029/2002GL015544, 2002.

Zhang, T. L., Nakamura, R., Volwerk, M., Runov, A., Baumjohann, W., Eichelberger, H. U., Carr, C., Balogh, A., Sergeev, V., Shi, J. K., and Fornacon, K.-H.: Double Star/Cluster observation of neutral sheet oscillations on 5 August 2004, Ann. Geophys., 23, 2909-2914, doi:10.5194/angeo-23-2909-2005, 2005. 